\title{
البحـث السـابع :
}

الإنتاج العلمي هن الكتب، والأبحاث المنشورة في المجلات العلميهية

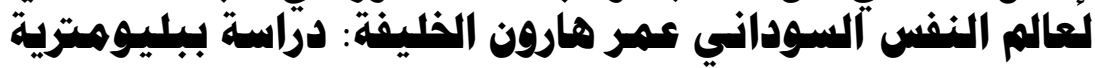

\section{: إحطاك}

أ.د. صلاح الدين فرح عطا الله بخيت

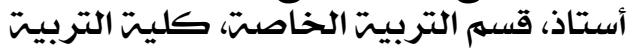

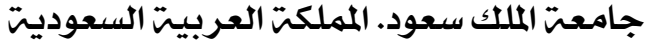

د. سامر إبراهيم باختي

أستاذ مشارك، قسم المكتبات والمعلومات المات

كليت الآداب، جامعت النيلين. السودان 



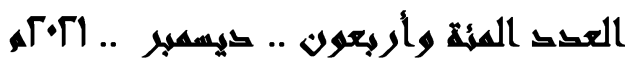

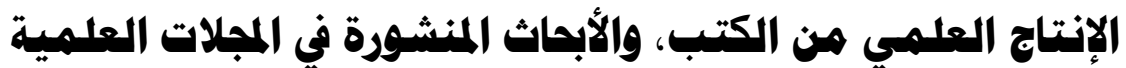

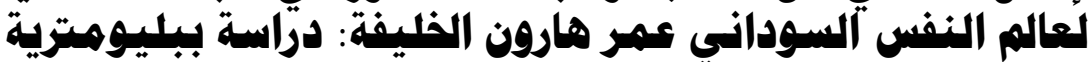

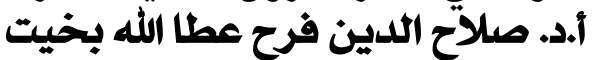

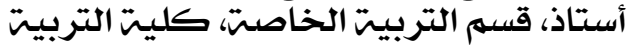

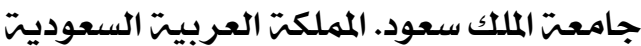

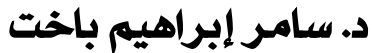

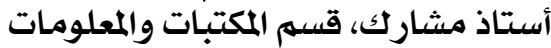 \\ كليت الآداب، جامعت النيلين. المكتيات المعلودات}

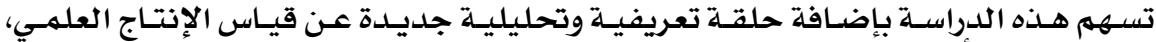

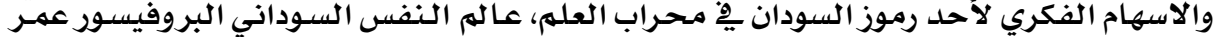

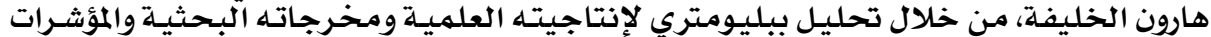

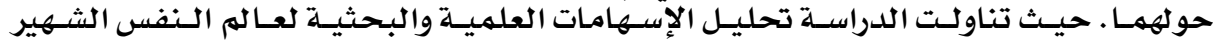

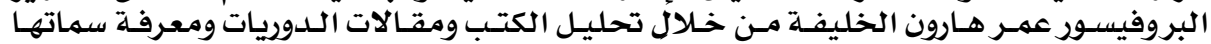

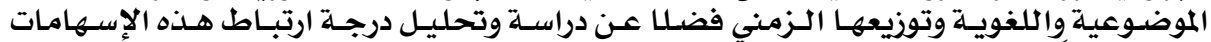

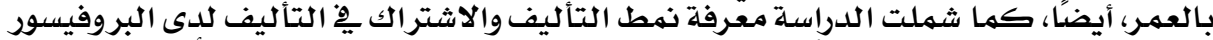

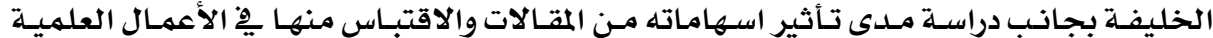

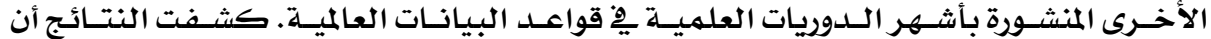

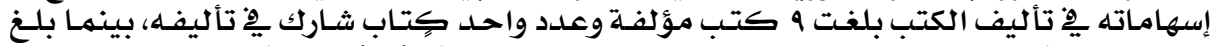

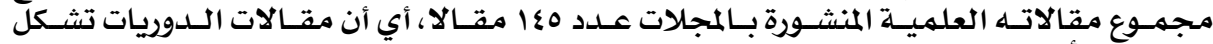

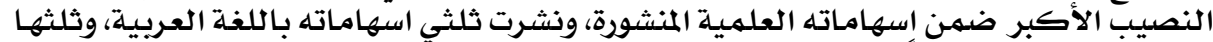

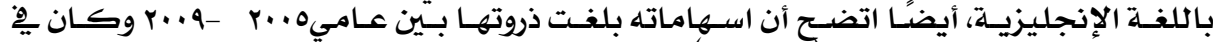

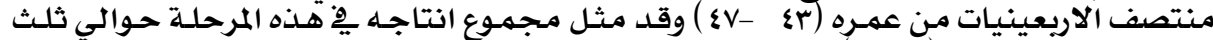

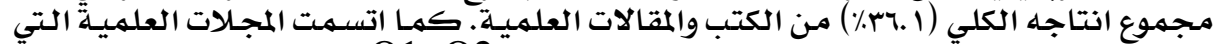

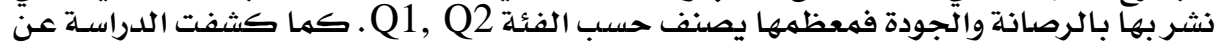

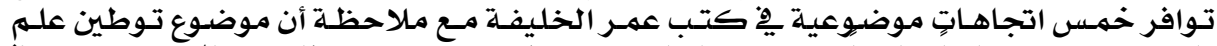

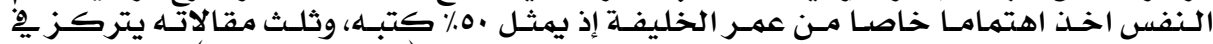

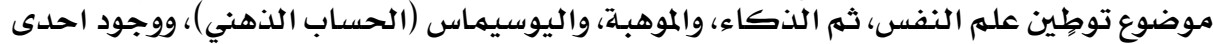

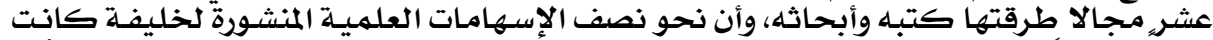

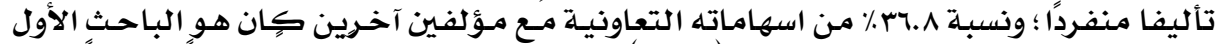

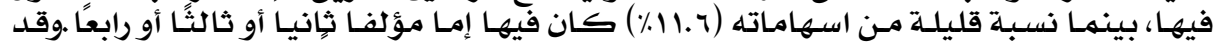

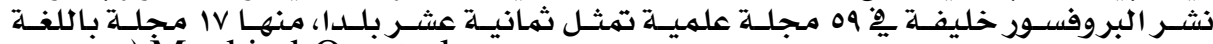

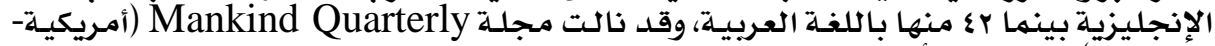

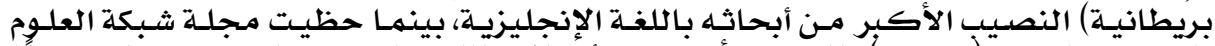

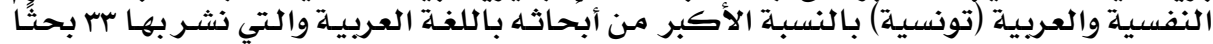

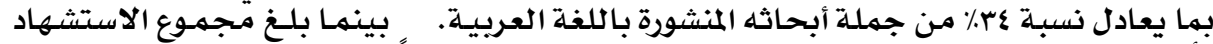

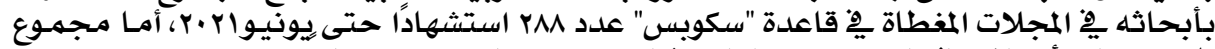

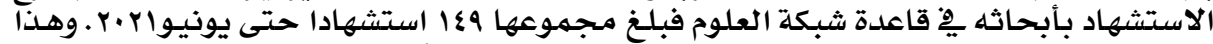

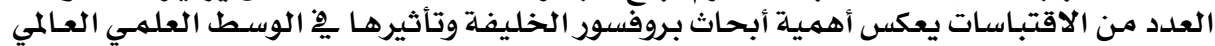

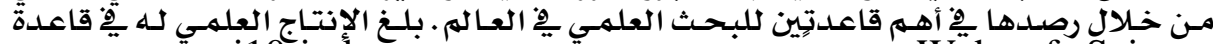

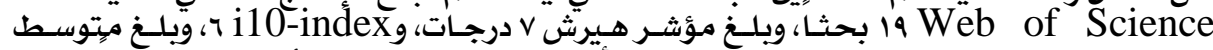

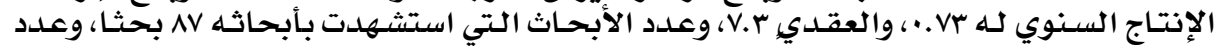

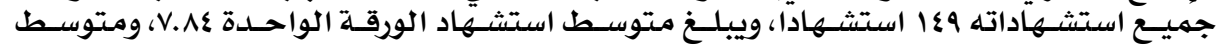

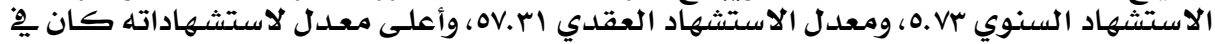




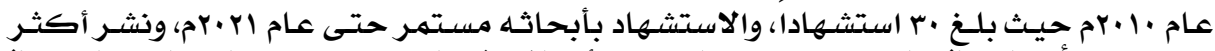

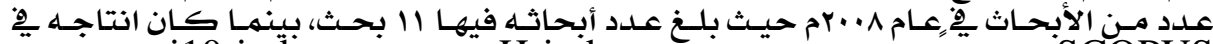

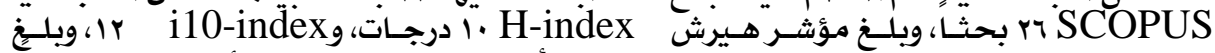

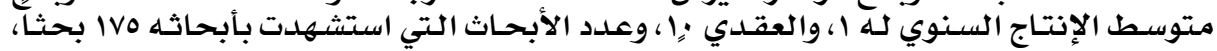

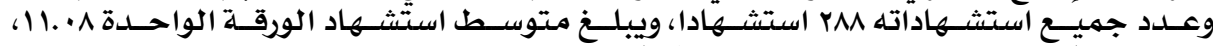

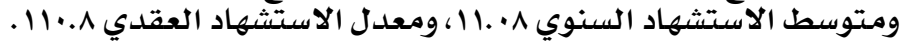

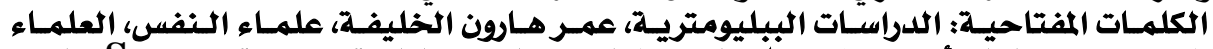

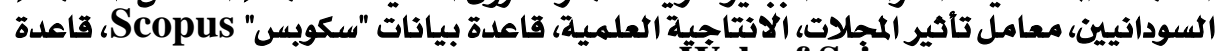

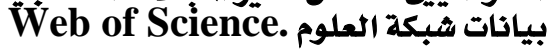

Scientific production of books and Articles in scientific journals by the Sudanese psychologist Omar Haroun Khaleefa: a bibliometric study

\section{Prof. Salaheldin Farah Attallah Bakhiet}

Dr. Samir Ibrahim Bakhit

\section{$\underline{\text { Abstract }}$}

This study contributes by adding a new introductory and analytical episode on measuring scientific production, and the intellectual contribution of one of the symbols of Sudan to the niche of science, the Sudanese psychologist Professor Omar Haroun Khaleefa, through a bibliometric analysis of his scientific productivity and research outputs and indicators around them. Where the study dealt with analyzing the scientific and research contributions of the famous psychologist Professor Omar Haroun Khaleefa through analyzing books and periodical articles and knowing their objective and linguistic features and their temporal distribution, as well as studying and analyzing the degree of correlation of these contributions with age, as well. In addition to studying the impact of his contributions from articles and quotes from them in other scientific works published in the most famous scientific journals in international databases. The results revealed that his contributions to writing books amounted to 9 authored books and one book he co-authored, while the total of his scientific articles published in Journals amounted to 145 articles, meaning that journal articles constitute the largest share among his published scientific contributions, and two thirds of his contributions were published in Arabic, and one third in English. , It also became clear that his contributions peaked between 2005-2009 and he was in his mid-forties (43-47), and his total production at this stage represented about a third of his total production $(36.1 \%)$ of books and scientific articles. The scientific journals in which he was published were characterized by sobriety and quality, most of which are classified according to the category Q1, Q2.The study also revealed the availability of five objective trends in the books of Omar Khaleefa, noting that the topic of indigenizing psychology took special attention from Omar Khaleefa, as it represents $50 \%$ of his books, and one third of his articles are focused on the topic of indigenizing psychology, then intelligence, Giftedness, and Ucimas (mental arithmetic). The existence of eleven fields covered by his books and research, and that about half of Khaleefa's published scientific contributions were a single authorship; And 36.8\% of his collaborative contributions with other authors were the first researcher in it, while a small percentage of his contributions (11.6\%) were either a second, third or fourth author.Professor Khaleefa has published in 59 scientific journals representing eighteen 


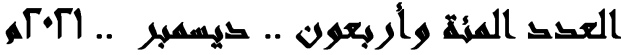

countries, of which 17 are in English and 42 are in Arabic. Mankind Quarterly (American-British) journal received the largest share of his research in English, while the Journal of Psychological Science and Arabic (Tunisian) received the largest share of his research. for the bulk of his research in the Arabic language, in which he published 33 papers, equivalent to $34 \%$ of the total of his research published in Arabic. While the total citations for his research in the journals covered in the Scopus reached 288 citations until June 2021, while the total citations for his research in the Web of Science reached 149 citations until June 2021. This number of citations reflects the importance of Professor Al-Khaleefa's research and its impact on the international scientific community by monitoring them in the two most important scientific research databases in the world.His scientific production in the Web of Science database has reached 19 papers, the Hirsch index is 7, the i10-index is 6 , the average annual production is 0.73 , the nodal is 7.3 , the number of research cited is 87 , and the number of all his citations is 149 , and the average citation is One paper is 7.84 , the average annual citation is 5.73 , the decadal citation rate is 57.31 , and the highest rate of citations was in 2010, when it reached 30 citations. His production in SCOPUS was 26 papers, the Hirsch index reached 10 degrees, the i10-index was 12, the average annual production was 1 , and the nodal 10 , the number of papers cited by his research was 175 , the number of all his citations was 288 , and the average citation per paper 11.08, average annual citation rate 11.08, and decadal citation rate 110.8 .

Keywords. Bibliometric studies, Omar Haroun Khaleefa, psychologists, Sudanese scientists, journals impact factor, scientific productivity, Scopus, Web of Science.

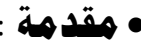

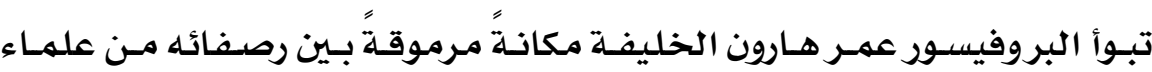

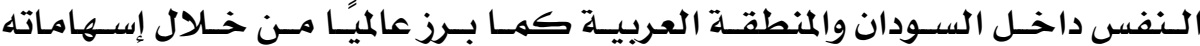

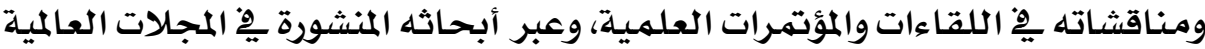

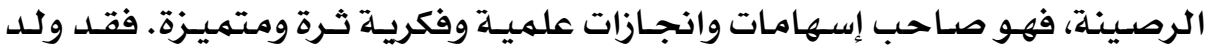

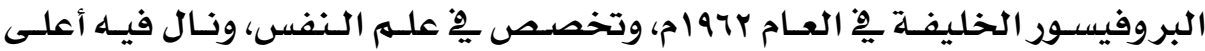

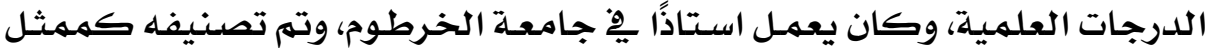

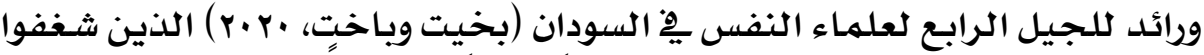

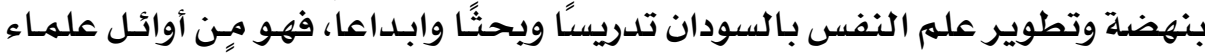

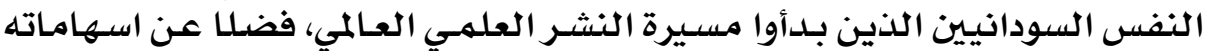

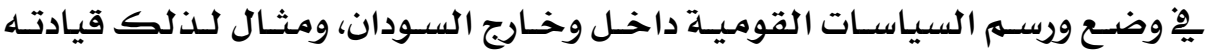

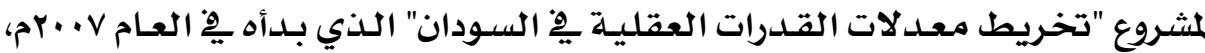

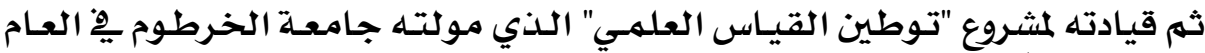

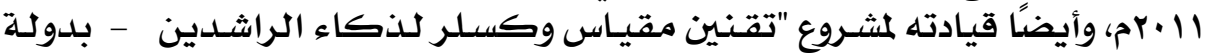

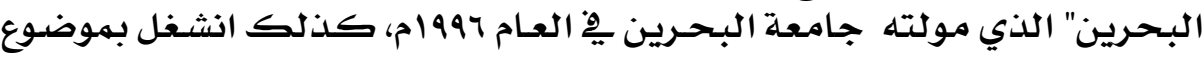

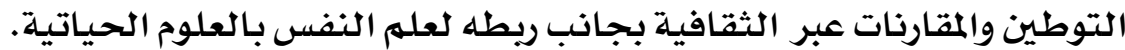




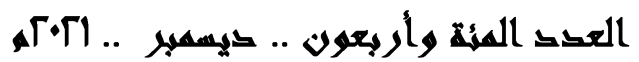

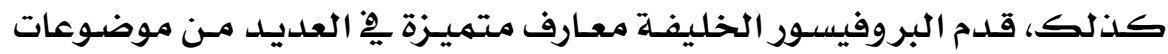

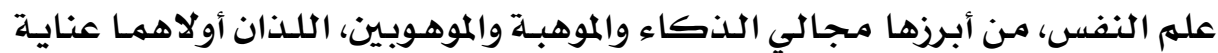

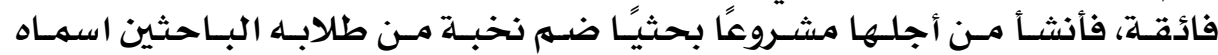

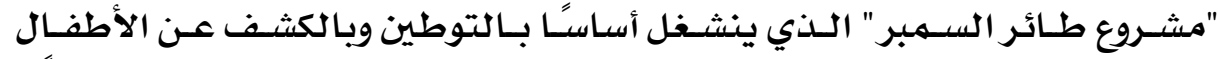

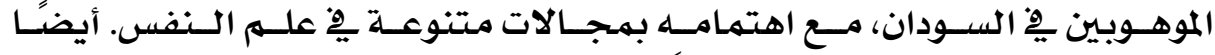

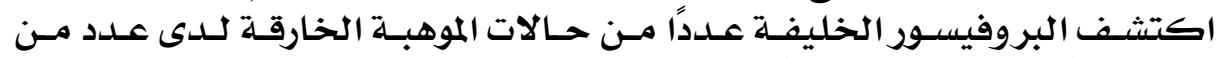

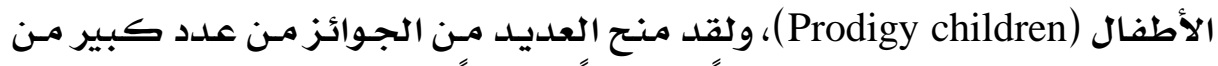

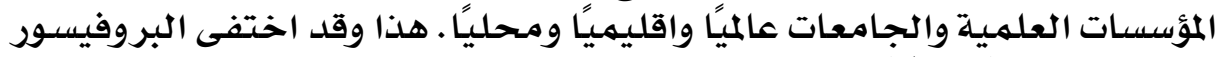

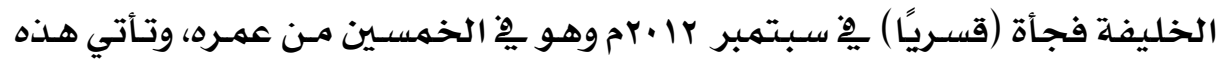

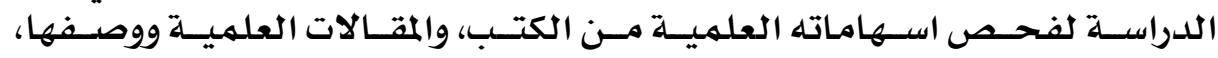
وتحليلها لمعرفة سماتها المختلفيلة.

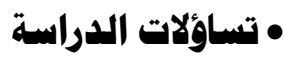

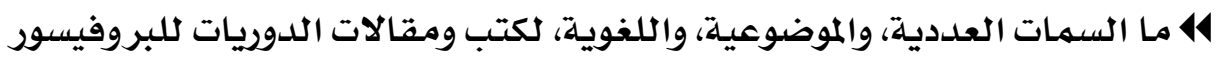

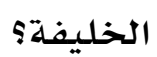
14 ما التوزيـع الزمني للكتب، والمقالات، التي نشرها البروفيسور الخليفة، وما درجـة

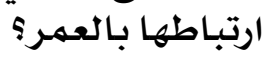

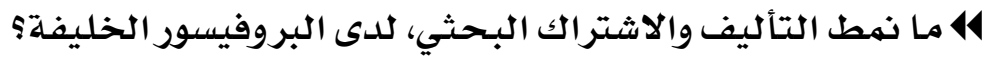

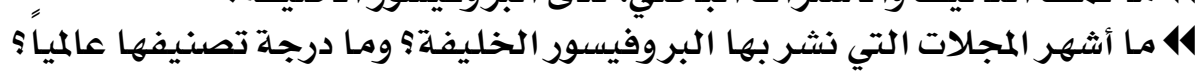

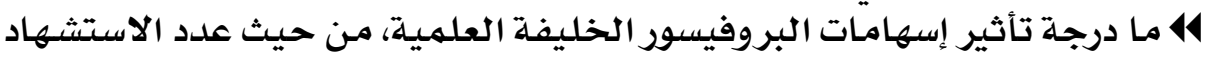

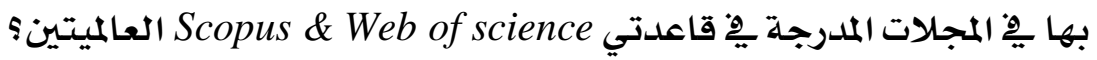
14

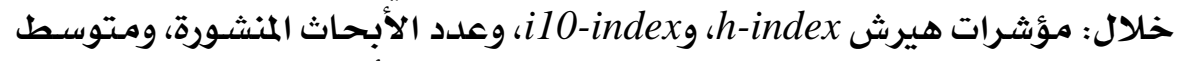

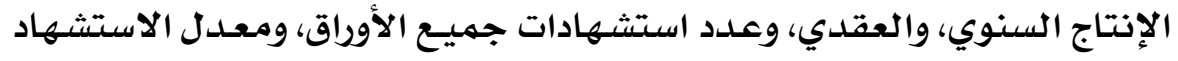

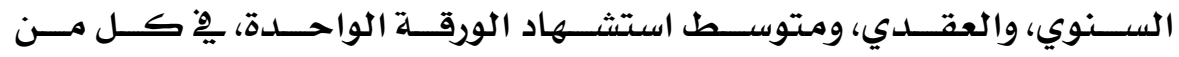

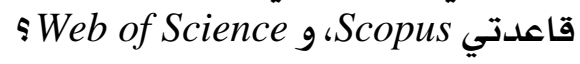

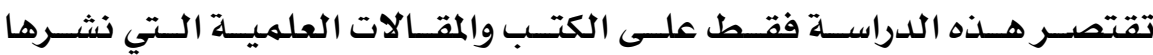

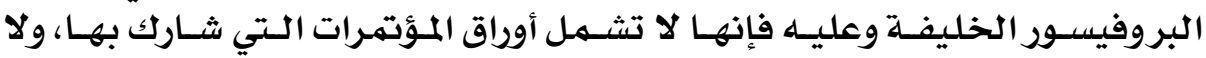

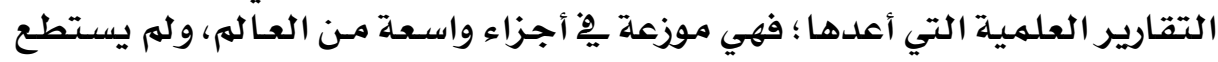

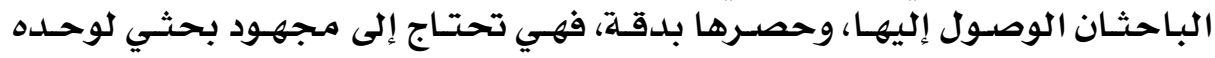

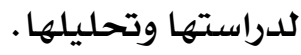

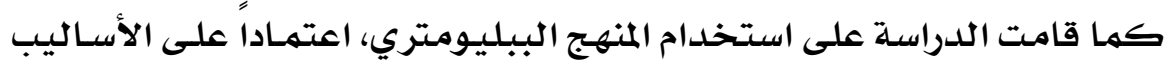

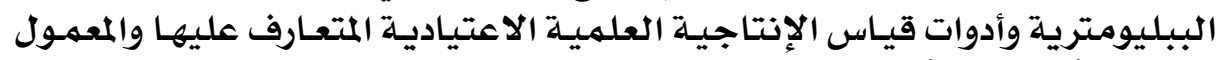

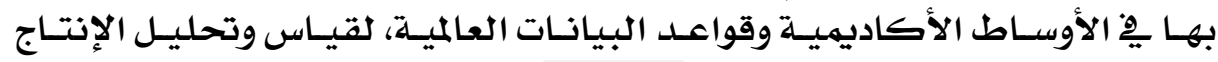




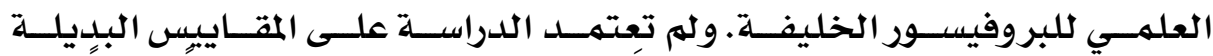

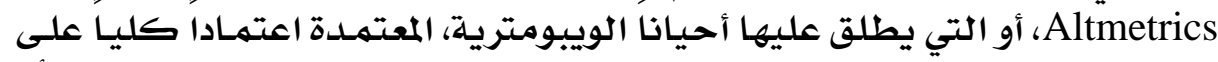

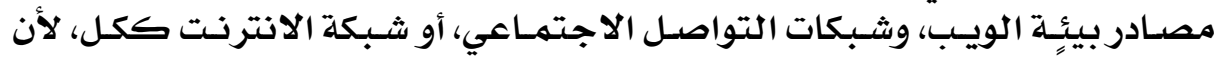

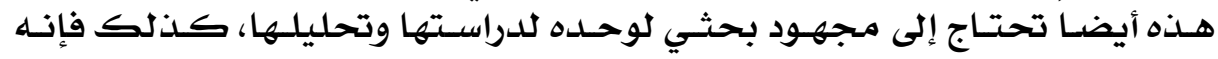

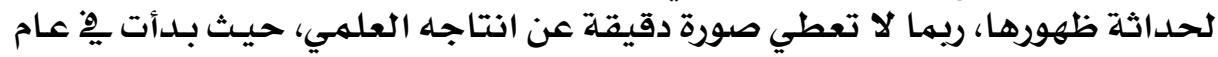

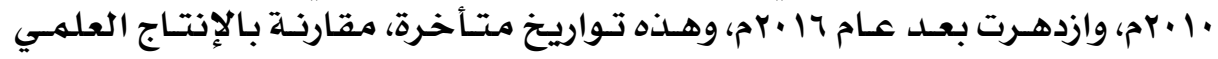

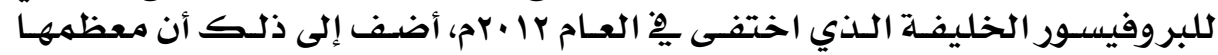

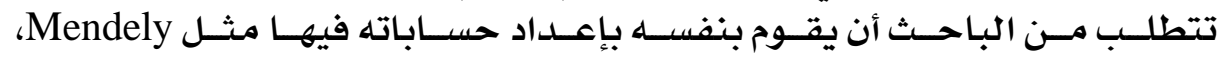
Buplons

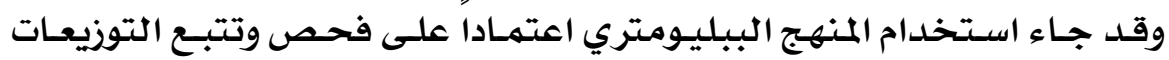

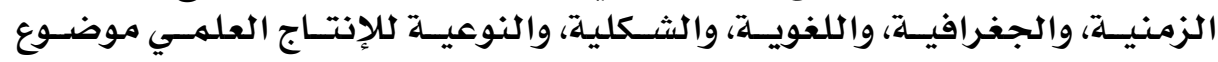

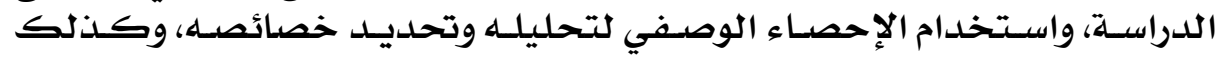

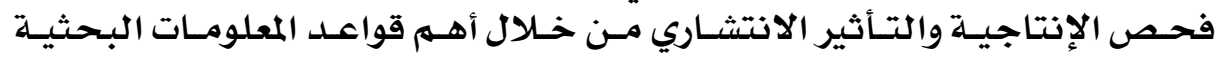
العالمية.

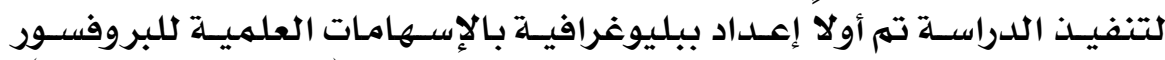

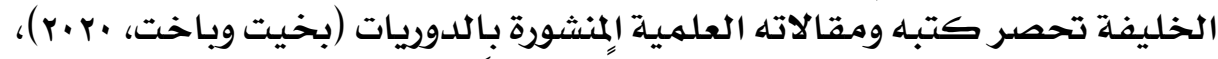

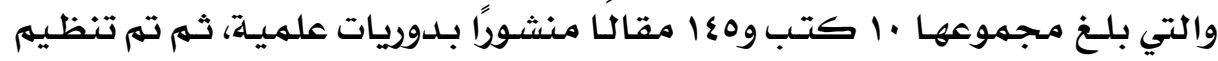

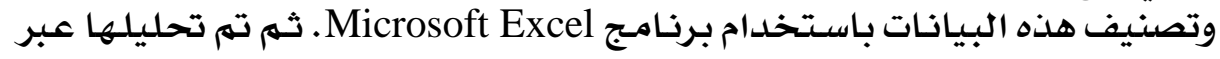

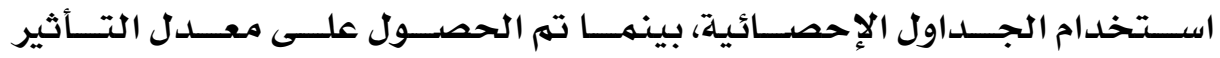
والاستشهادات لمقالات البروفيسور خليفة بالاستناد إلى قاعدتي of science • الدراسات السابقة لم تجر دراسـات سـابقة مفصسلة عن تحليـل وقياس الإنتـاج العلهـي للبروفيسـور

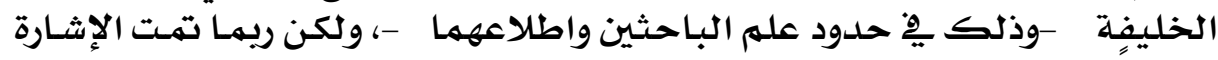

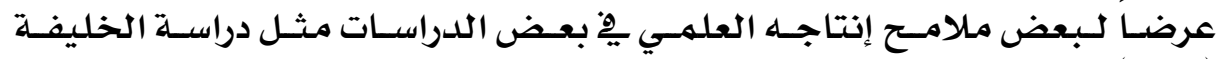

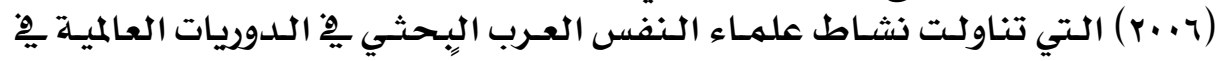

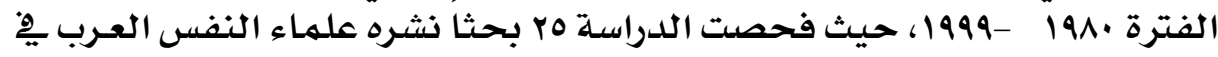
الدورية عالميلة، وقد تم تصنيف هذا الإنتاج العلهي يخ ه مجالات لعلم النفس هي:

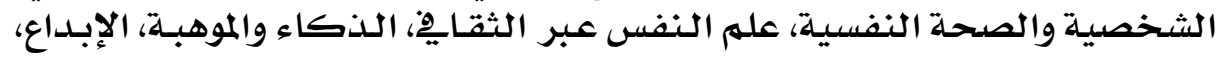

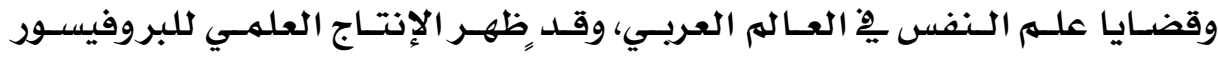

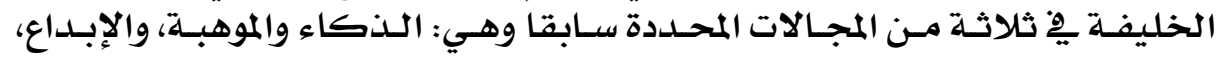

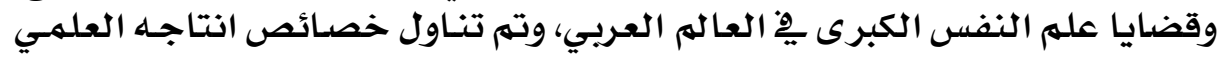

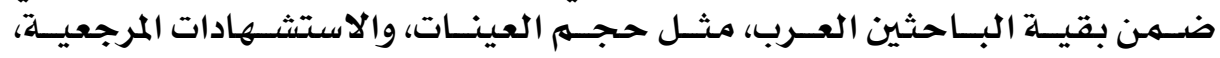
وخصائص التأليف. 


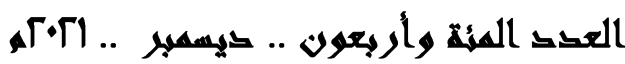

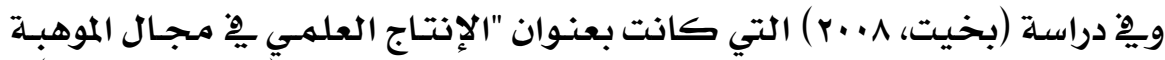

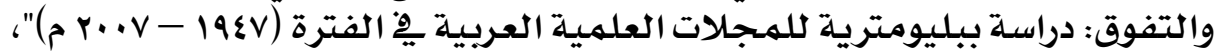

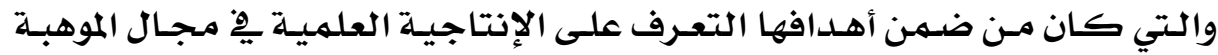

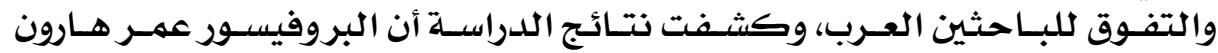

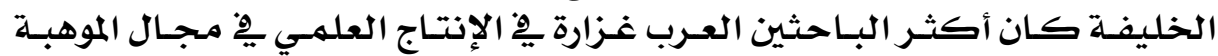

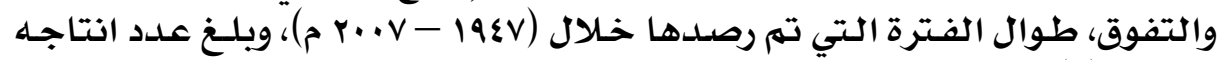
العلهي (q) أبحاث.

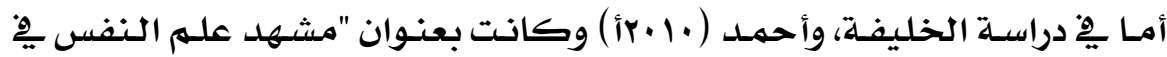

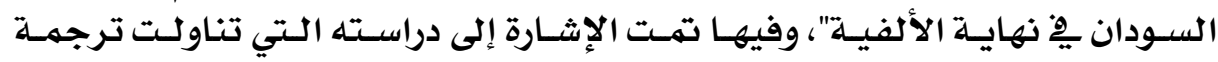

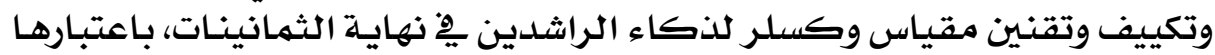

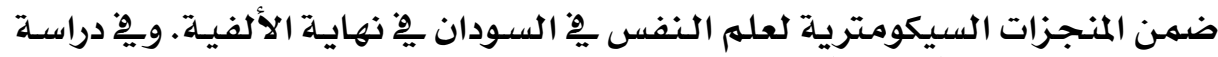

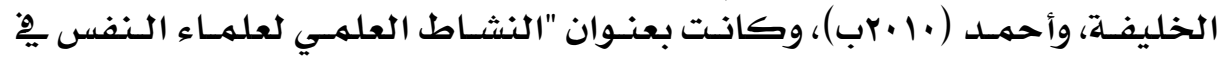

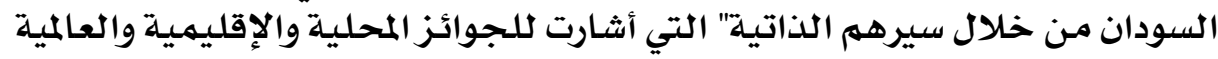

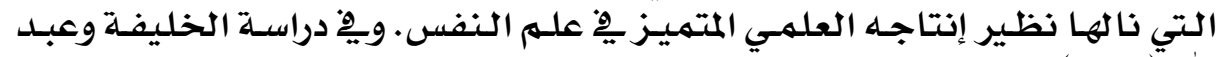

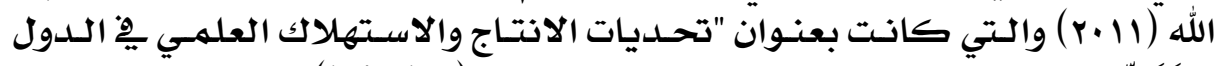

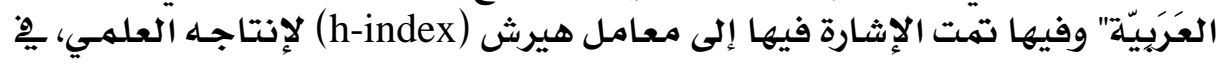

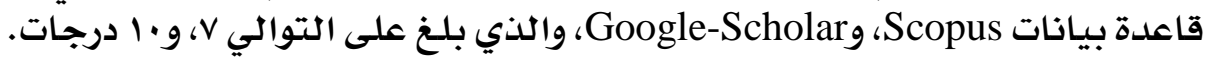

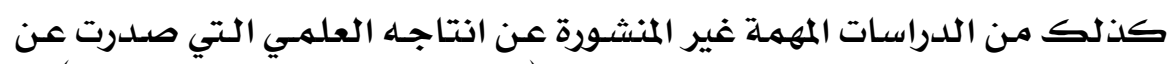

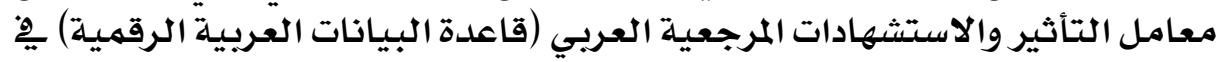

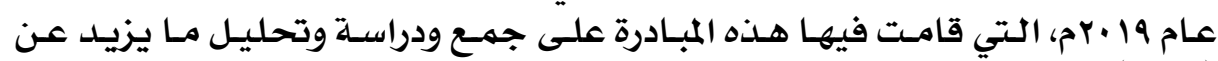

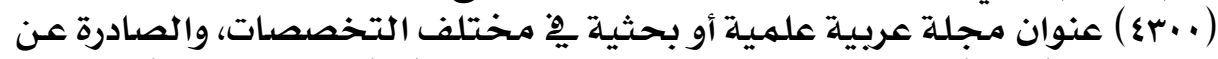

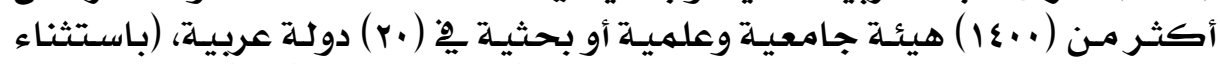

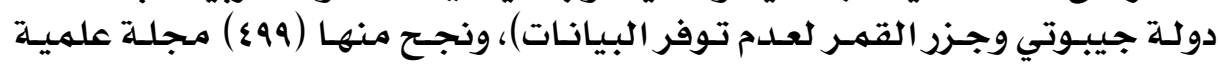

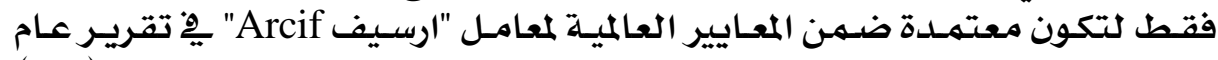

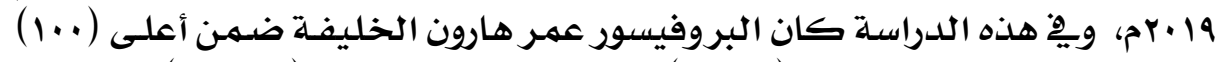

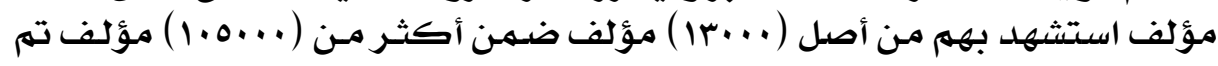

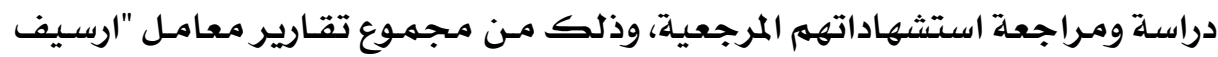
Arcif

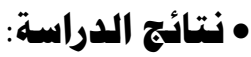

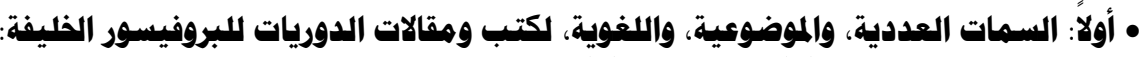

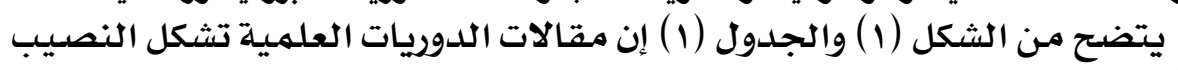

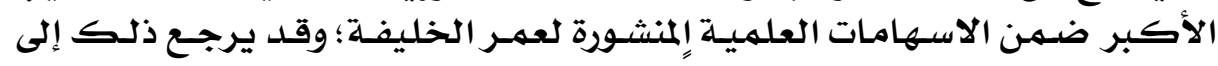

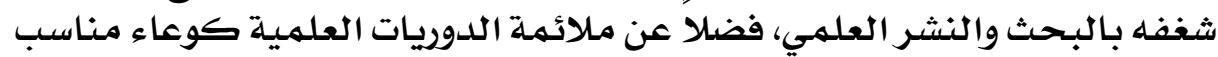




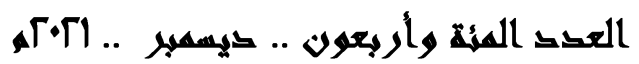

$93.50 \%$

$100.00 \%$

$80.00 \%$

$60.00 \%$

$40.00 \%$

$20.00 \%$

$0.60 \%$

$5.80 \%$

$0.00 \%$

الفصول المحررة في الكتب مقالات الاوريات العلمية

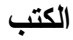

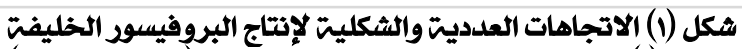

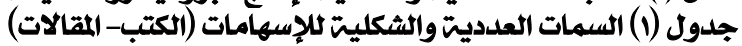

\begin{tabular}{|c|c|c|}
\hline النسبتة & التكراد & اثكال الاسهامات المنشورة \\
\hline $5.8 \%$ & 9 & الكتب \\
\hline $0.6 \%$ & 1 & الفصول المحررة 2خ الكتب \\
\hline $93.5 \%$ & 145 & مقالات الدوريات العلميت \\
\hline $100.0 \%$ & 155 & المجموع \\
\hline
\end{tabular}

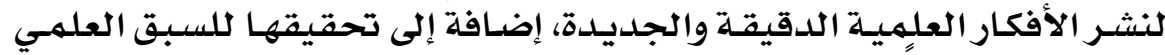

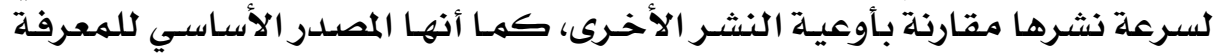

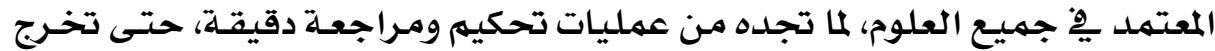

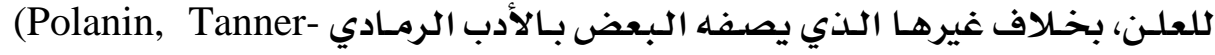
.Smith, and Hennessy, 2016)

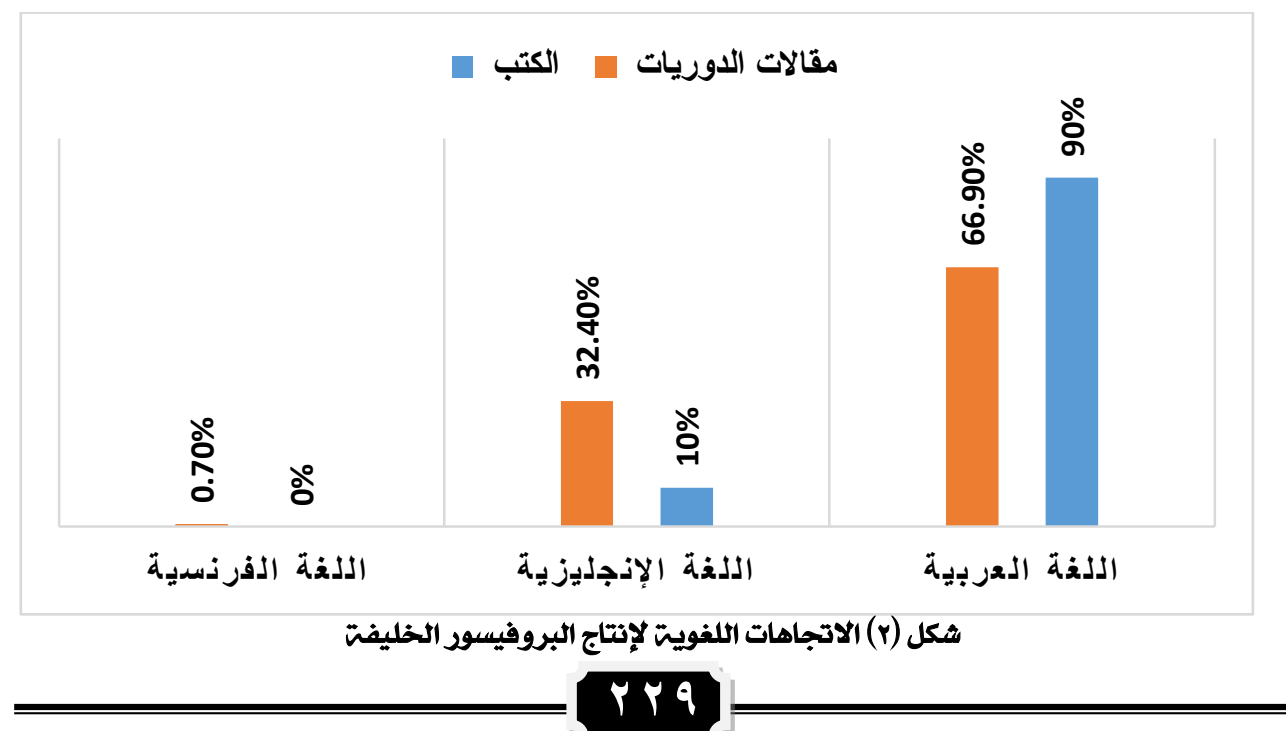




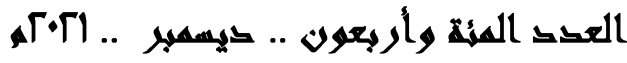

جدول (r) الاتجاهات اللغويت للإسهامات المنشورة

\begin{tabular}{|c|c|c|c|c|c|c|}
\hline \multicolumn{2}{|c|}{ المجموع } & \multicolumn{2}{|c|}{ مقالات الدوريات } & \multicolumn{2}{|c|}{ الكتب } & \multirow{2}{*}{ اللغات } \\
\hline & التكرارات & التسبية & التكرارات & النسبتة & التكرارات & \\
\hline $68.4 \%$ & 106 & $66.9 \%$ & 97 & $\% 90$ & & اللفتشالعربية \\
\hline $31.0 \%$ & 48 & $32.4 \%$ & 47 & $\%$ & 1 & اللفتش الإنجليزية \\
\hline $0.6 \%$ & 1 & $0.7 \%$ & & $\%$ & & اللفت الفرنسيت \\
\hline$\%$ & 155 & $100.0 \%$ & 145 & $\%$ & 10 & المجموع \\
\hline
\end{tabular}

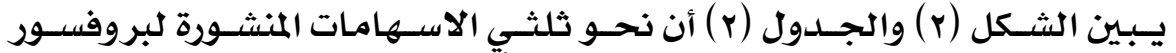

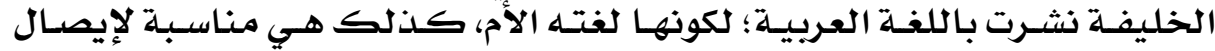

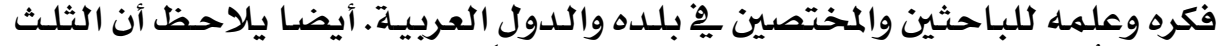

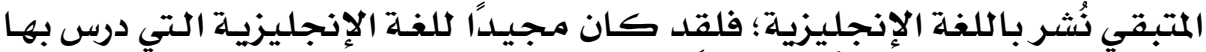

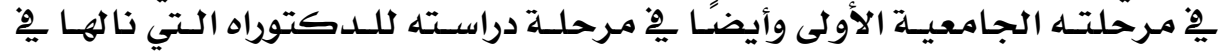

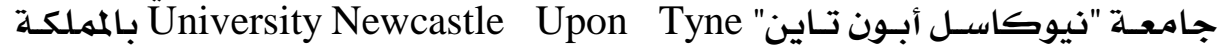
المتحدة في العام 1990.

جدول (r) الاتجاهات الموضوعيت والزمنيت والمكانيت والعلدديت للكتب

\begin{tabular}{|c|c|c|c|c|c|c|}
\hline الصفلحات & الدولتة & دار النثر & السنتة & الموضوع & الكتاب & $p$ \\
\hline 92 & ت ت تونس & مؤسسستيت العلوميتي & 2013 & التعليم وقضاياه & دماغ أمتَِِِ خطر & 1 \\
\hline 600 & الأردن & دار ديبونوز للنشر & 2012 & توطين علم & مأزق علماء الثفلى 2 & 2 \\
\hline 600 & الأردن & دار ديبونتو للنشر & 2012 & اليوسيماس| الخسباب/ الذهني & وتفريزيج طأيوا & 3 \\
\hline 131 & تونس & النفوسيتيت العلويتيت & 2011 & توطينِ علم & 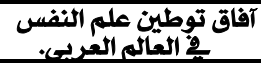 & 4 \\
\hline 486 & الأردن & دار الفكر & 2009 & توطين علم & 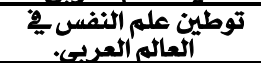 & 5 \\
\hline 338 & الأردن & دار ديبونو للنشر & 2008 & الموهيت والتفوق & 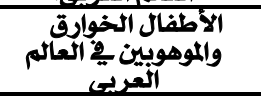 & 6 \\
\hline 174 & السبودان & هيثت الأممال الفكريت & 2008 & توطين علم & آفاق توطين ملم النفس & 7 \\
\hline 44 & بريطاذ & $\begin{array}{c}\text { Cambridge } \\
\text { university } \\
\text { press }\end{array}$ & 2006 & الابداع - الاع & $\begin{array}{c}\text { African } \\
\text { perspectives on } \\
\text { creativity }\end{array}$ & 8 \\
\hline 444 & لبنان & المؤسسراست العربيتي & 2001 & توطين علم & علم النفري التجريبي - الإسلامئي & 9 \\
\hline 315 & لبنان & اللمؤسسترات والعربيتشر & 2000 & علم النفابر & علم النفس والمخابرات & 10 \\
\hline
\end{tabular}

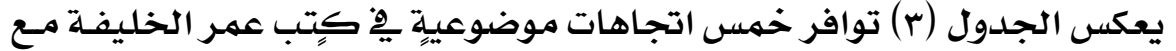

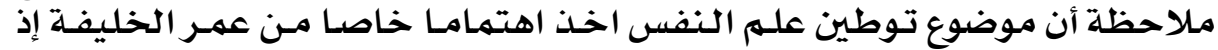

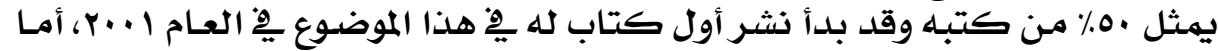

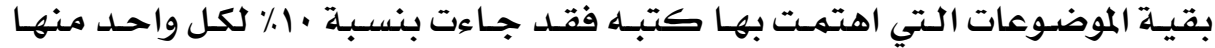

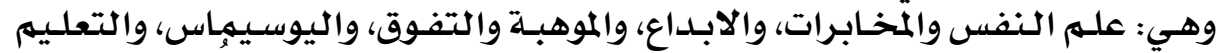

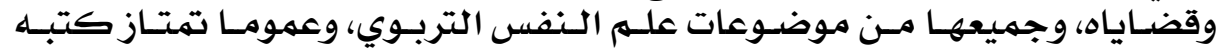

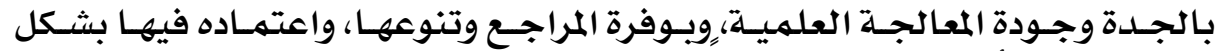
أساسي على الأبحاث المنشورة عالمالميا. 


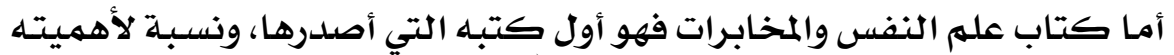

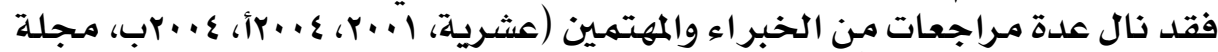

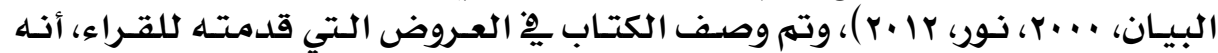

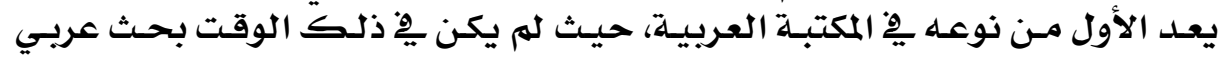

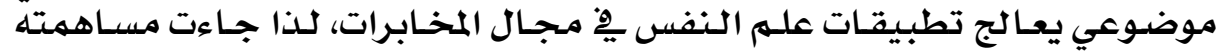

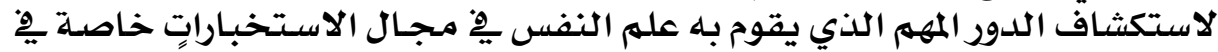

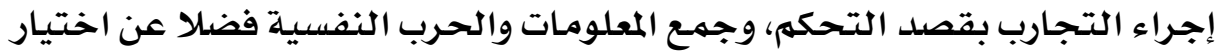

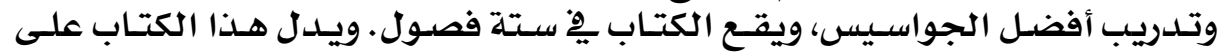

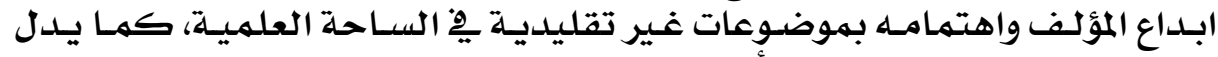

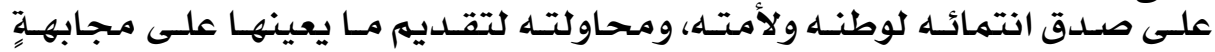

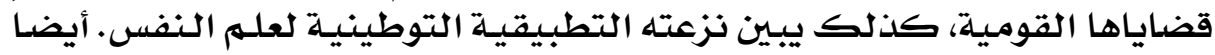

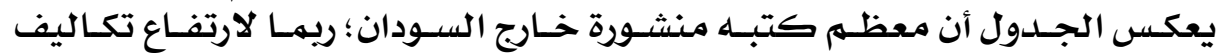
الطباعة والنشر بالسودان.

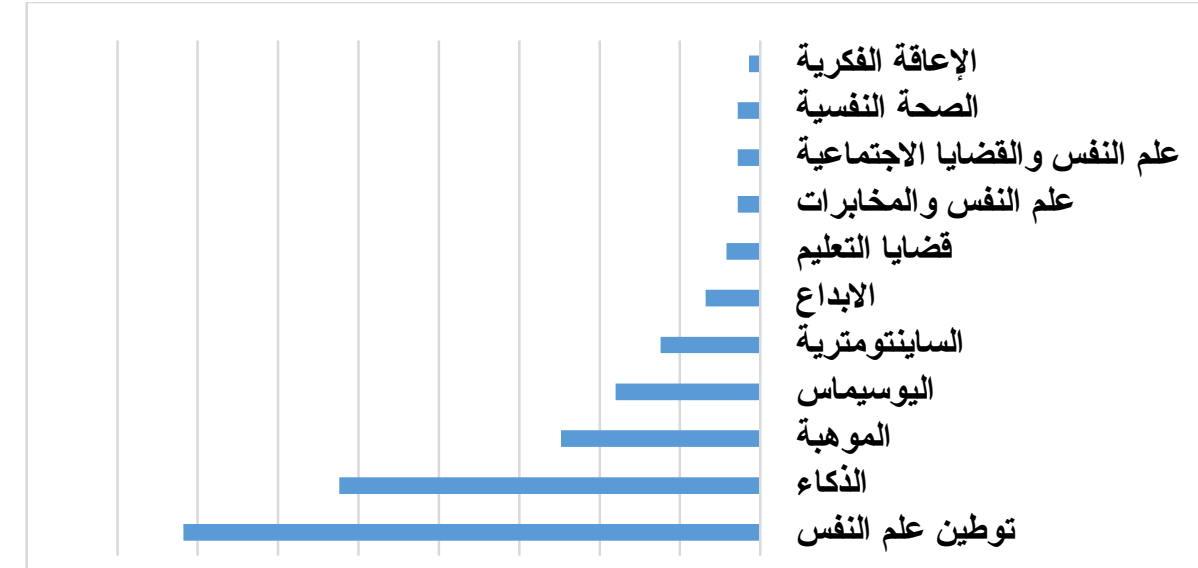

40.00\%5.00\%0.00\%.00\%0.00\%5.00\%0.00\%.00\% $0.00 \%$

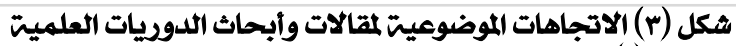

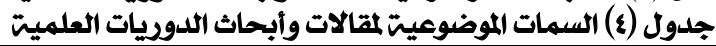

\begin{tabular}{|c|c|c|c|}
\hline | النسبت & عدد المقالات & الموضوعات & الرقيم \\
\hline $35.9 \%$ & 52 & توطين علم النفس & 1 \\
\hline $26.2 \%$ & $\overline{38}$ & الذكاء الذياء & 2 \\
\hline $12.4 \%$ & 18 & الموهية & $\overline{3}$ \\
\hline $9.0 \%$ & 13 & اليوسيماس & 4 \\
\hline $6.2 \%$ & 9 & الساينتومتريتً & 5 \\
\hline $3.4 \%$ & 5 & الالابداع & 6 \\
\hline $2.1 \%$ & 3 & قضايا التعليم & 7 \\
\hline $1.4 \%$ & $\frac{2}{2}$ & علم النفس والمخابرات & 8 \\
\hline $1.4 \%$ & $\overline{2}$ & علم النفص والقضايا الاجتماعيت & 9 \\
\hline $1.4 \%$ & $\frac{2}{2}$ & |الصحت النفسيت & 10 \\
\hline $0.7 \%$ & 1 & |لاعاقت الفكريتً & 11 \\
\hline $100.0 \%$ & $\overline{145}$ & المجموع & \\
\hline
\end{tabular}




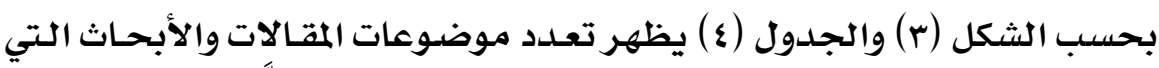

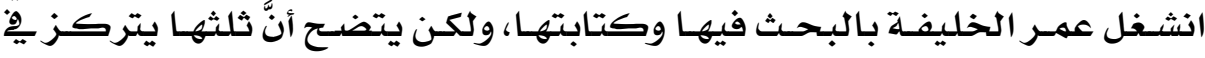

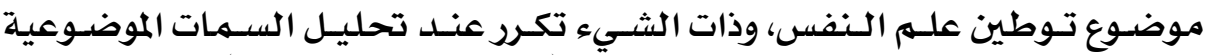

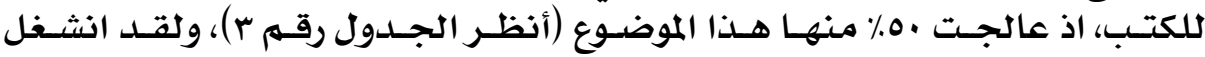

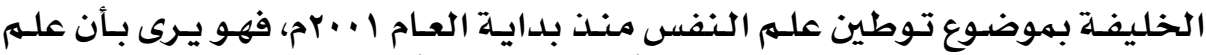

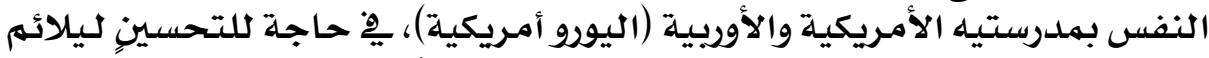

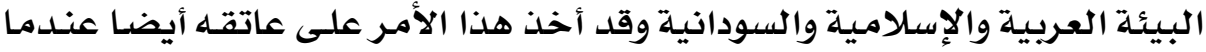

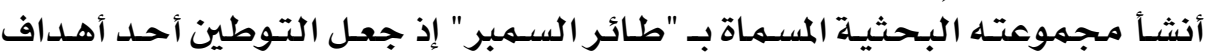

مجموعته.

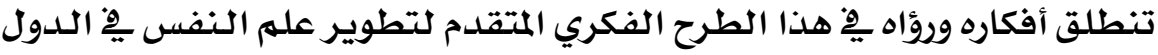

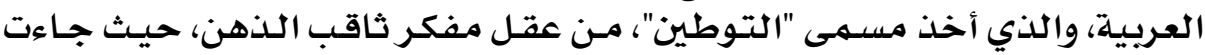

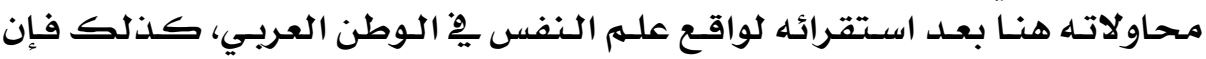

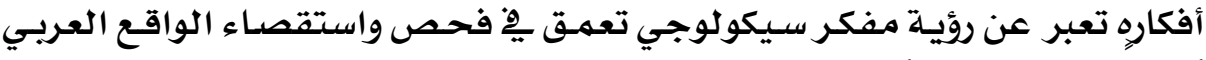

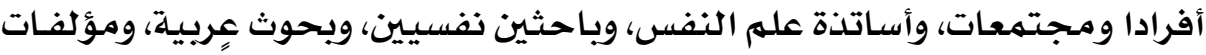

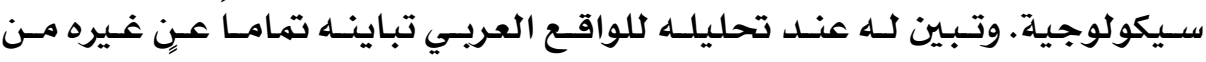

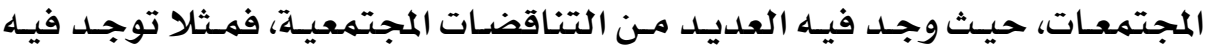

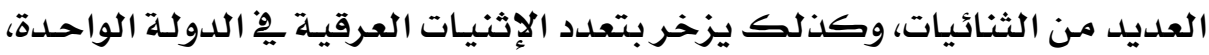

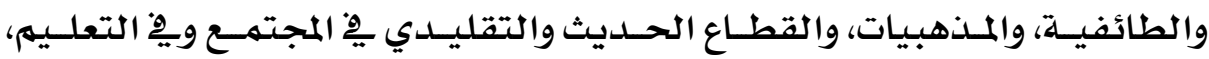

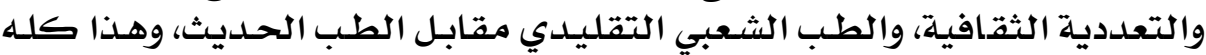

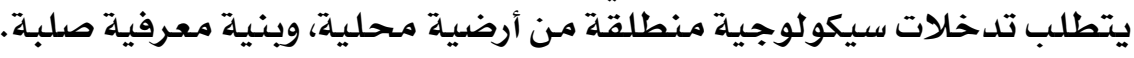

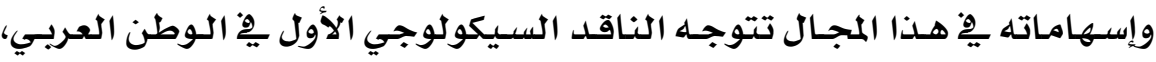

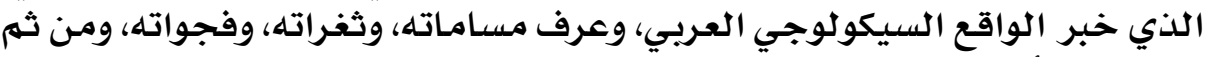

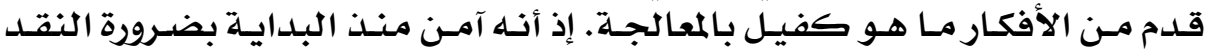

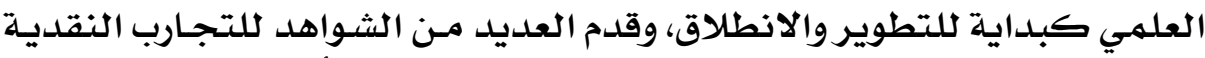

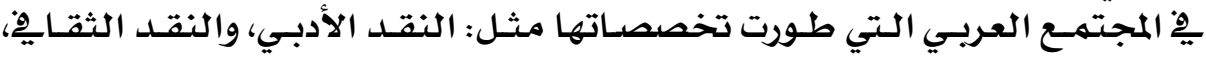

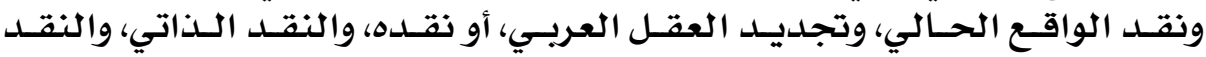

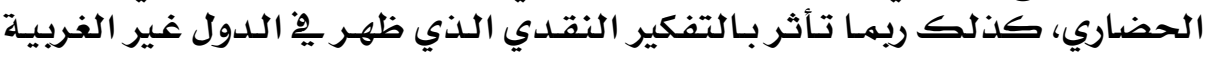

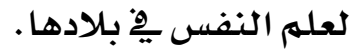

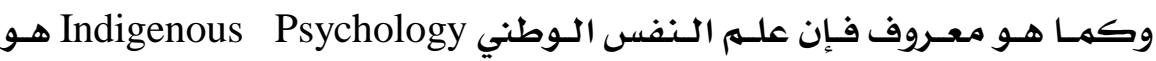

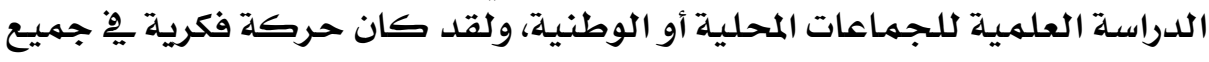

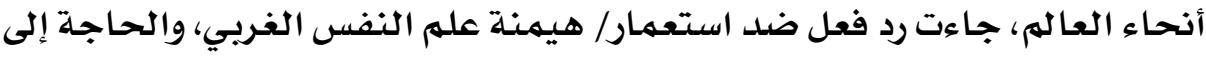

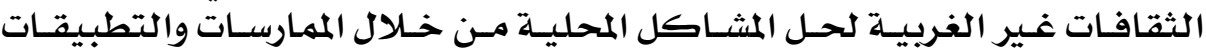

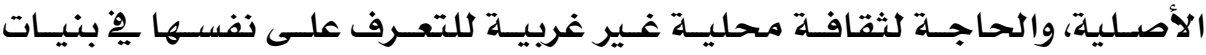




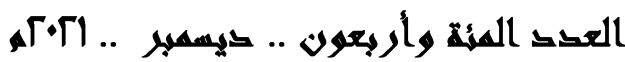

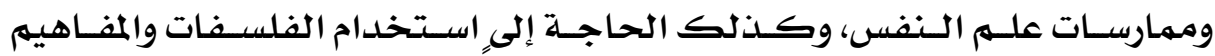

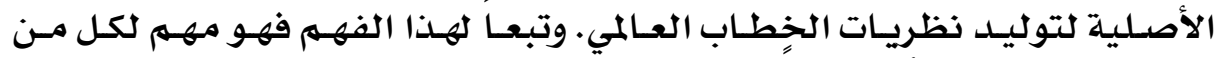

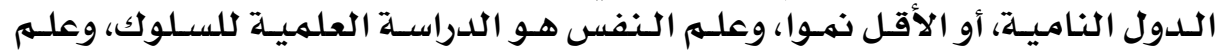

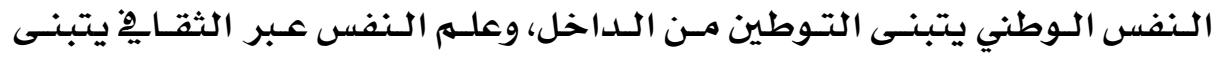

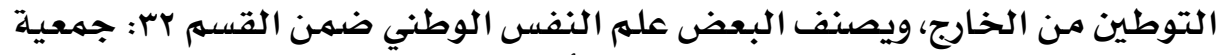
علم النفس الإنساني، من أقسـام الجمعية الأمـريكية لعلهم النفس.

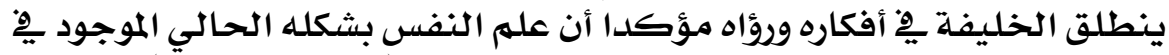

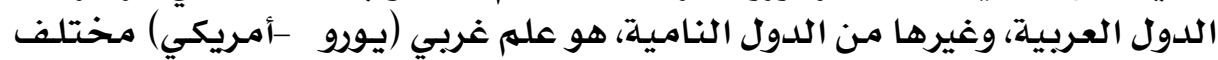

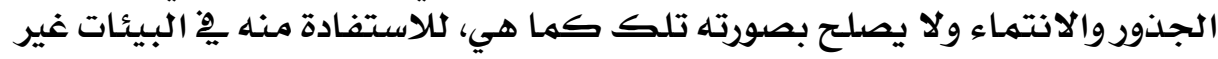

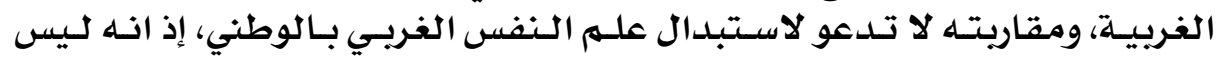

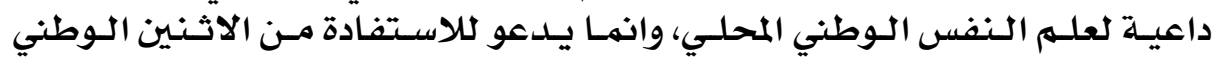
والموطن.

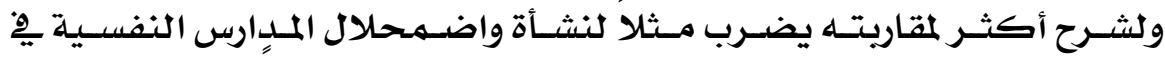

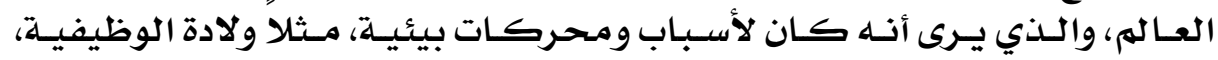

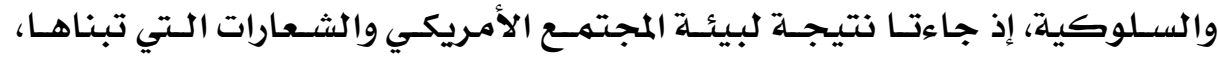

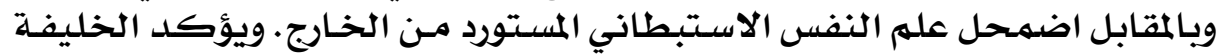

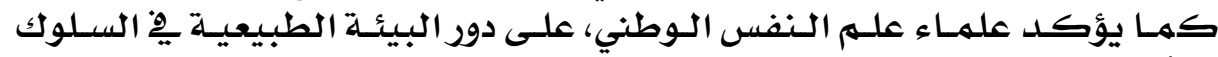

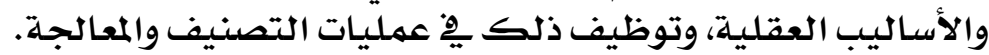

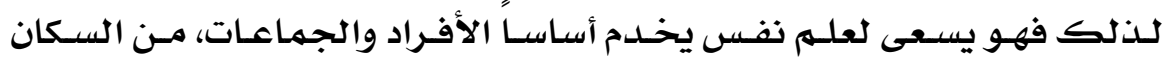

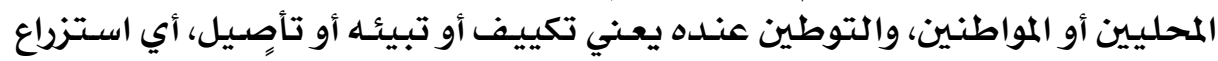

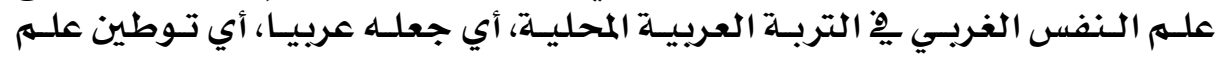

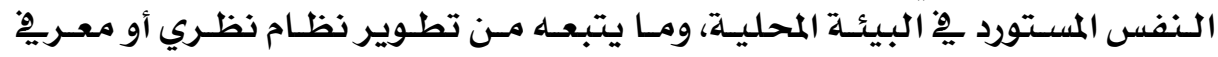

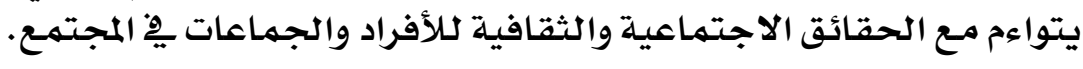

بهعنى أن جماع رؤاه وأفكاره يِّ التوطين هو الاسـفادة مـن علـم النفس التوطني

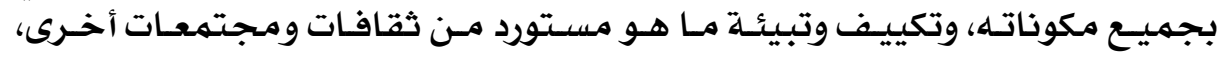

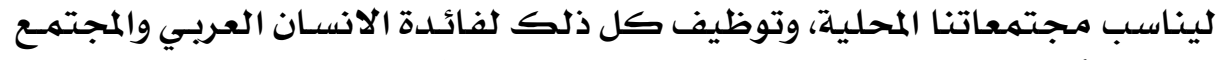

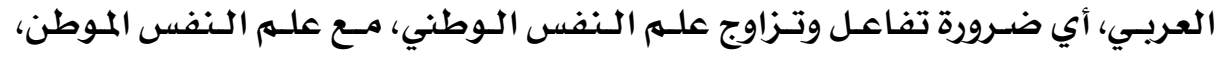

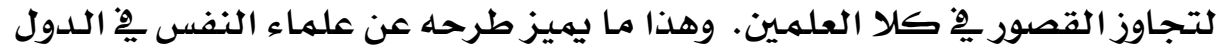

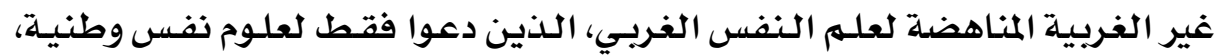

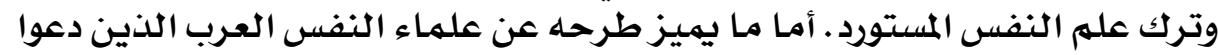

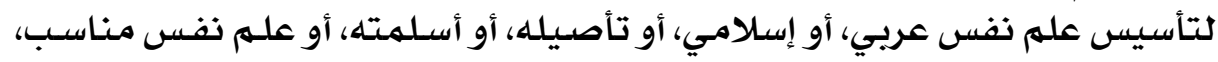

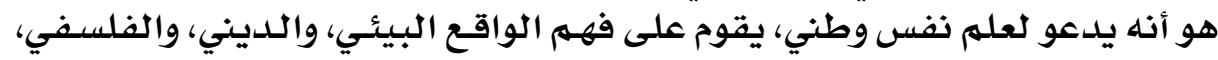

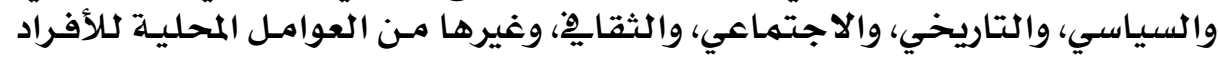




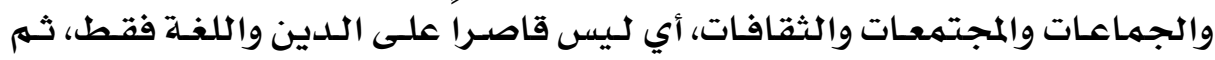

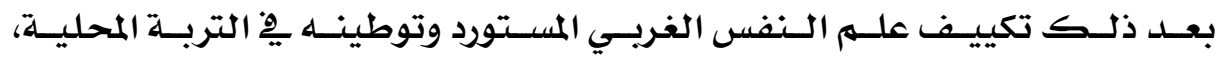

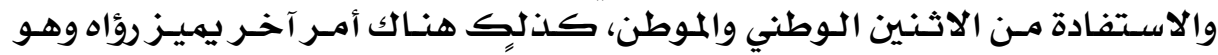

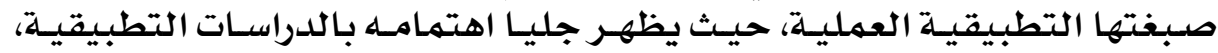

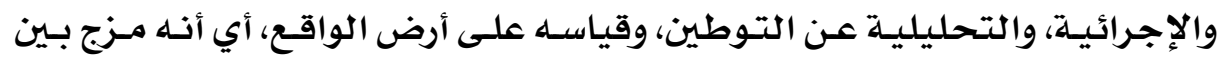

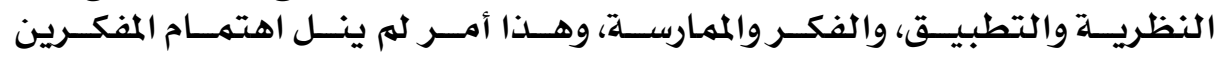

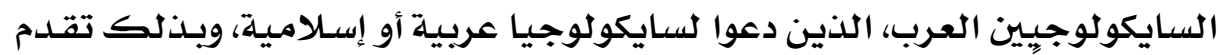

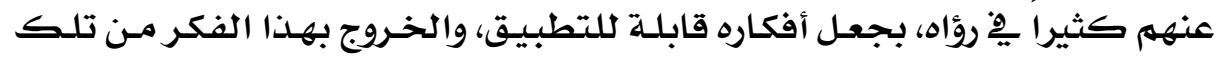

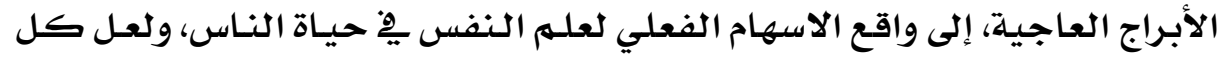

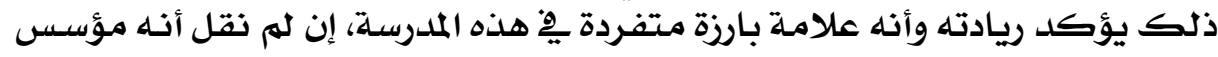

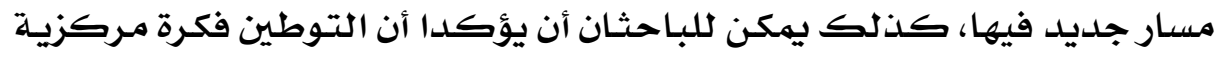

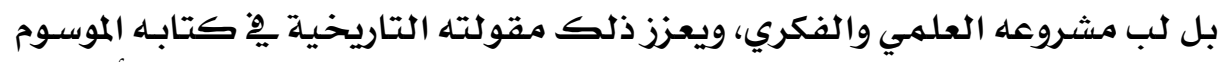

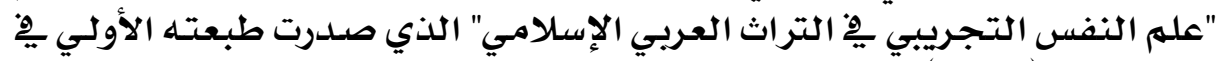

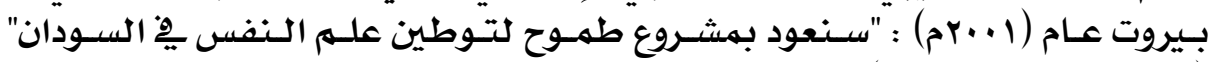

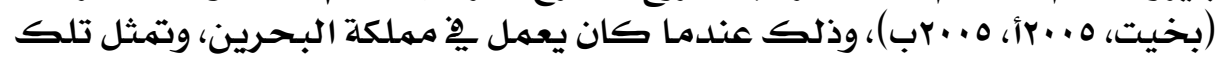

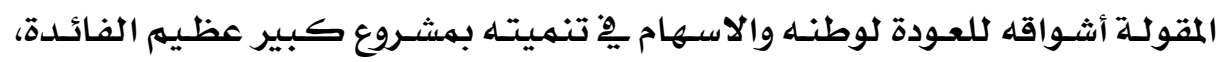

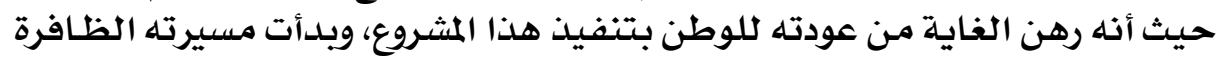

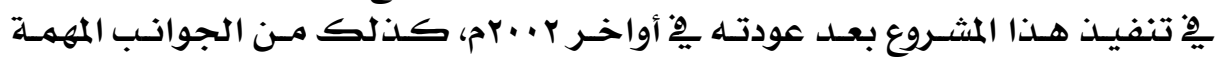

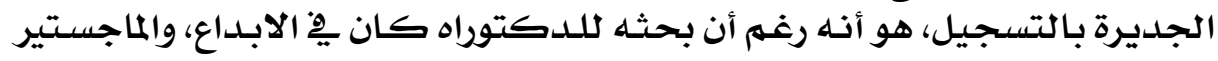

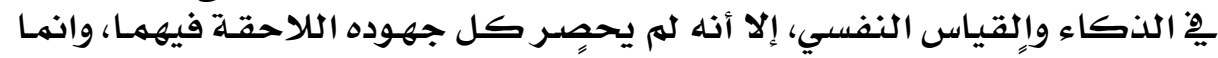

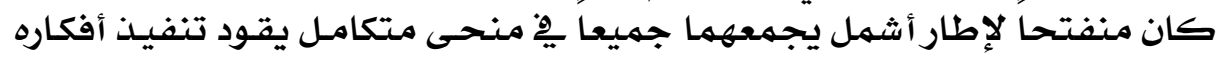
واهتهماماته البحثيـة كانية كافية.

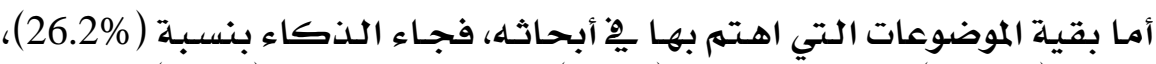

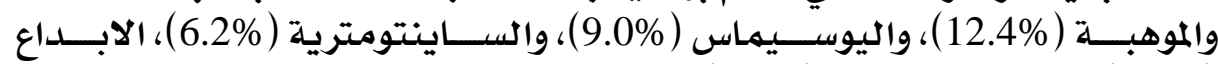

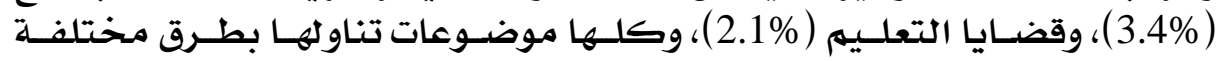

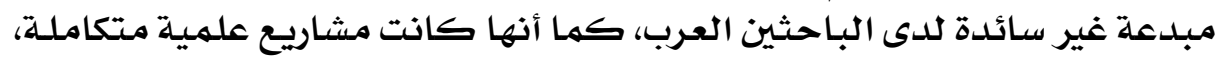

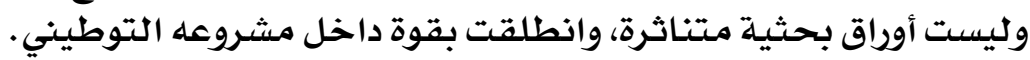

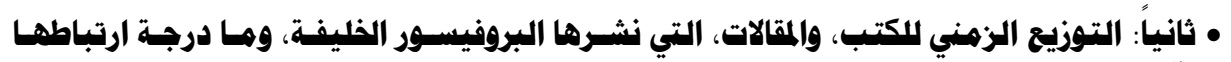

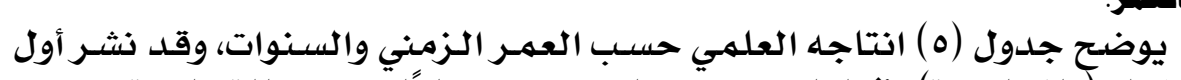

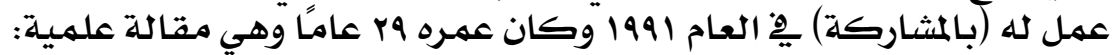
Salih, M., Khaleefa, O., Bushara, M., Taha, Z., Musa, Z., Kamil, I., Hofvander, Y., Olcen, P. (1991). Long term sequelae of childhood acute bacterial meningitis in a developing country. Scandinavian Journal of Infectious Diseases, 23, 175-182 (Sweden). 


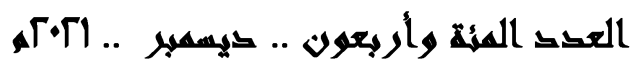

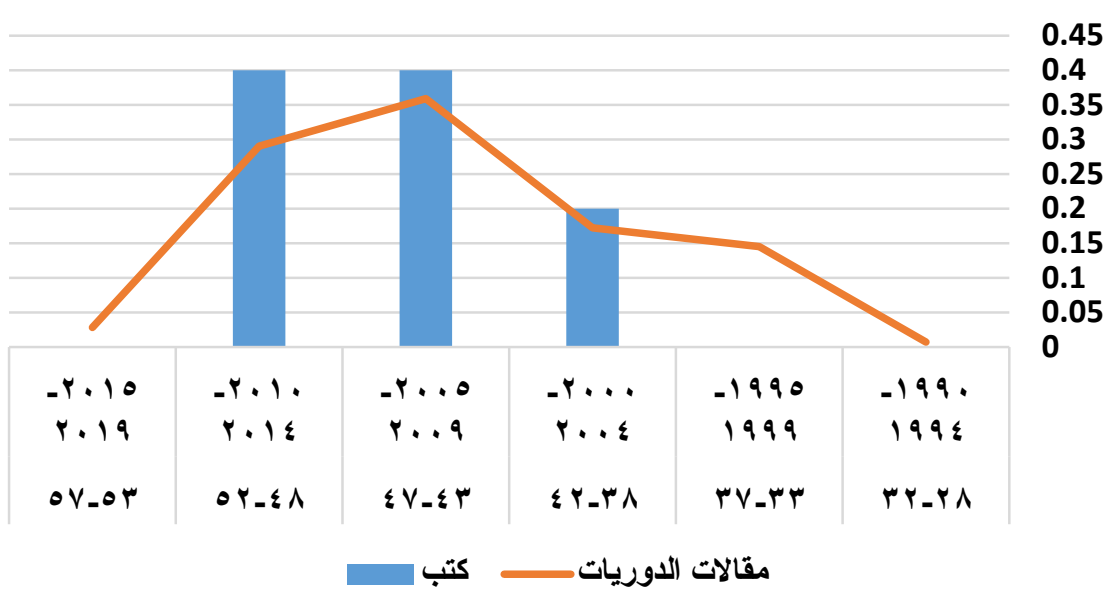

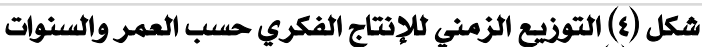

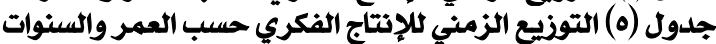

\begin{tabular}{|c|c|c|c|c|c|c|c|}
\hline \multicolumn{2}{|c|}{ المجموع } & \multicolumn{2}{|c|}{ مقالات الدوريات } & \multicolumn{2}{|c|}{ كتب } & \multirow[t]{2}{*}{ السنوات } & \multirow[t]{2}{*}{ العمر } \\
\hline نسبتة & تكرارات & نسبتة & تكرارات & نسبت & تكرارات & & \\
\hline $0.6 \%$ & 1 & $0.7 \%$ & 1 & - & - & 1994-1990 & $32-28$ \\
\hline $13.5 \%$ & 21 & $14.5 \%$ & 21 & - & - & 1999_1995 & 37-33 \\
\hline $17.4 \%$ & 27 & $17.2 \%$ & 25 & $20.00 \%$ & 2 & $2004-2000$ & 42-38 \\
\hline $36.1 \%$ & 56 & $35.9 \%$ & 52 & $40.00 \%$ & 4 & 2009-2005 & $47-43$ \\
\hline $29.7 \%$ & 46 & $29.0 \%$ & 42 & $40.00 \%$ & 4 & $2014-2010$ & $52-48$ \\
\hline $2.6 \%$ & 4 & $2.8 \%$ & 4 & - & - & 2019-2015 & $57-53$ \\
\hline $100.0 \%$ & 155 & $100.0 \%$ & 145 & $100.00 \%$ & 10 & جموع & \\
\hline
\end{tabular}

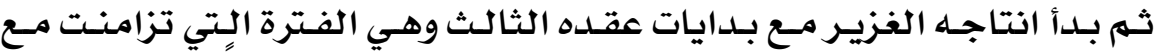

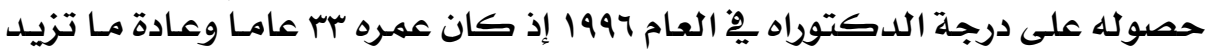

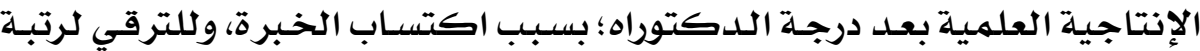

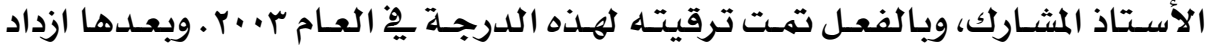

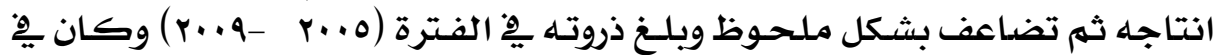

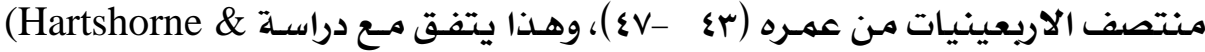
(Germaine, 2015، الـتي شـارك فيها

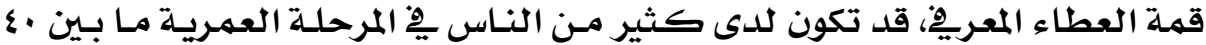

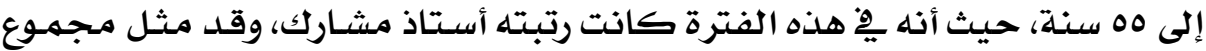

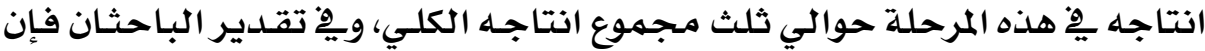

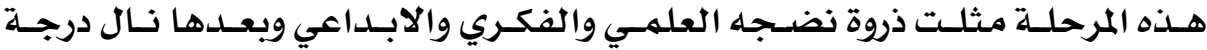

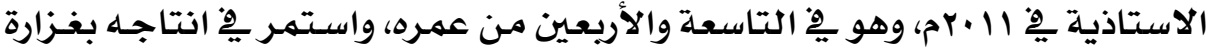

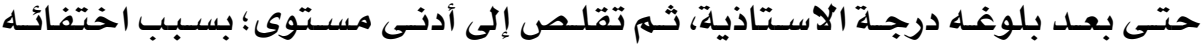

\section{YHO}




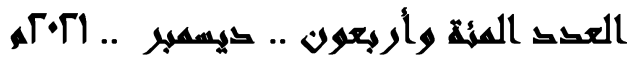

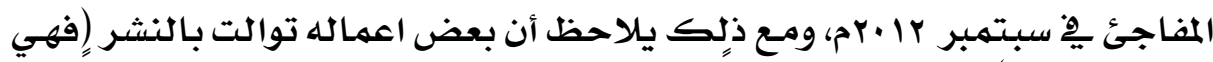

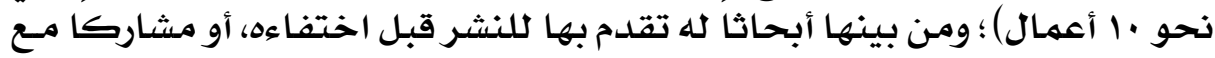

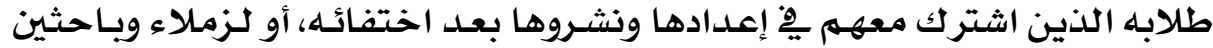

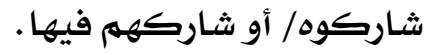

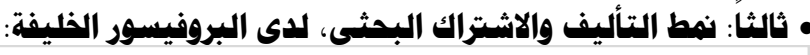

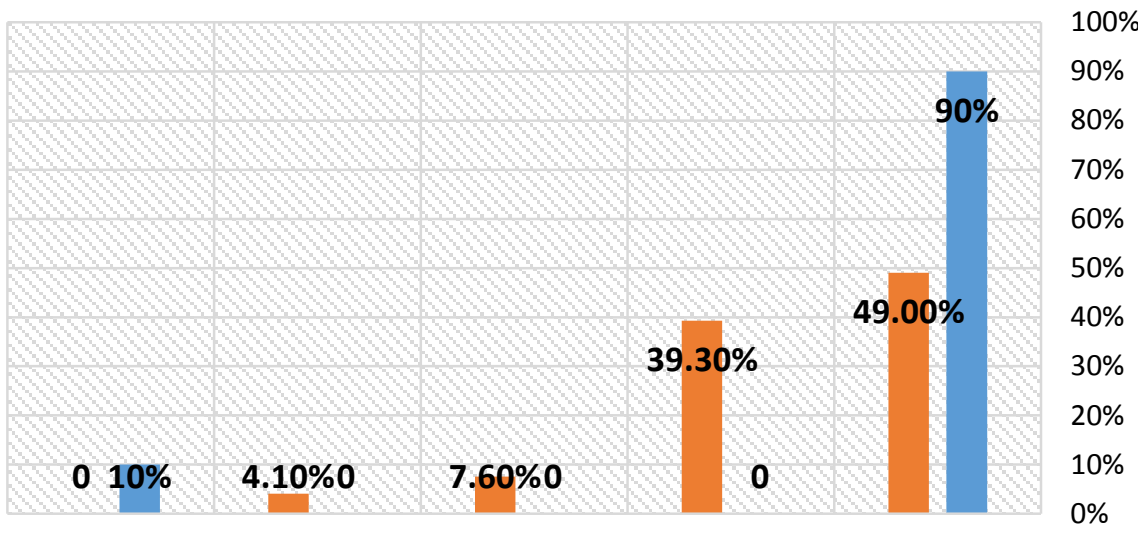

التأليف المنفرد مؤلف أول مؤلف ثاني مؤلف ثالث مؤلف رابع فأكثر

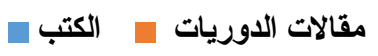

شكل (ه) نمط التاليف يُ الأعمال المثشورة للبروفيسور الخليفت

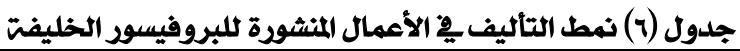

\begin{tabular}{|c|c|c|c|c|c|c|}
\hline \multicolumn{2}{|c|}{ المجموع } & \multicolumn{2}{|c|}{ مقالات الدور رات } & \multicolumn{2}{|c|}{ الكت } & \multirow[b]{2}{*}{ مسؤوليتة التاليف } \\
\hline النسيت & التكرارات & النسبتة & التكرارات & النسبية & التكرارات & \\
\hline $51.6 \%$ & 80 & $49.0 \%$ & 71 & $\% 90$ & 9 & التاليف المنفرد \\
\hline $36.8 \%$ & 57 & $39.3 \%$ & 57 & - & - & مؤلف أول \\
\hline $7.1 \%$ & 11 & $7.6 \%$ & 11 & - & - & مؤلف ثاني \\
\hline $3.9 \%$ & 6 & $4.1 \%$ & 6 & - & - & مؤلف ثالث \\
\hline $0.6 \%$ & 1 & - & - & $\% \mathbf{1 0}$ & 1 & مؤلف رابع فاكثر \\
\hline $100.0 \%$ & 155 & $100.0 \%$ & 145 & $\% \mathbf{1 0 0}$ & 10 & المجموع \\
\hline
\end{tabular}

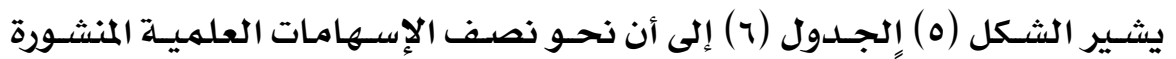

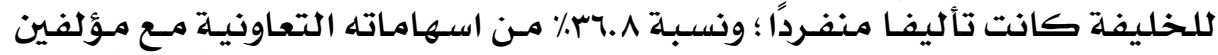

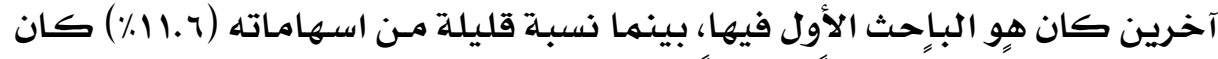

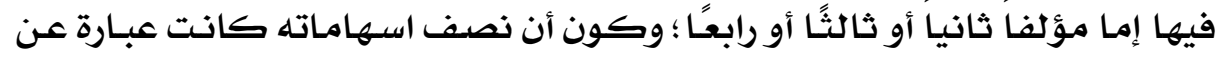

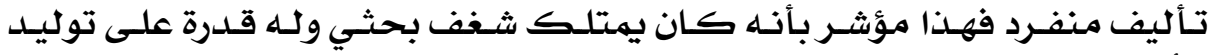

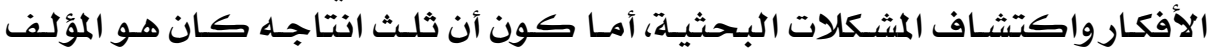

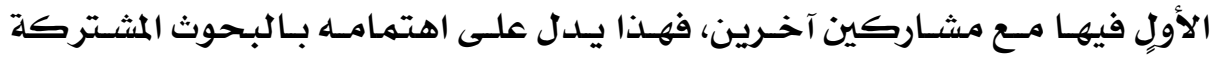
فضلا عن قدرته على قيادة الفرق البـحثية. 


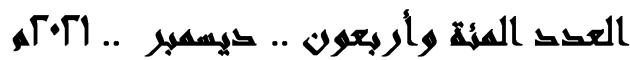

• رابعاً: أشهر المجلات التي نشر بها البروفيسور الخليفة؟ ودرجة تصنيفها عالمياً:

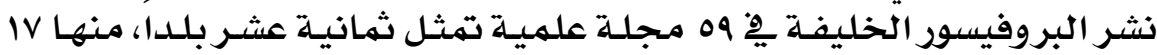

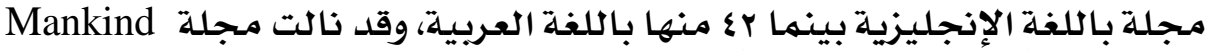
Quarterly

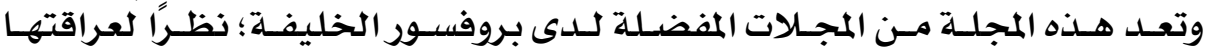

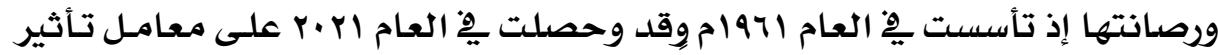
Impact Factor

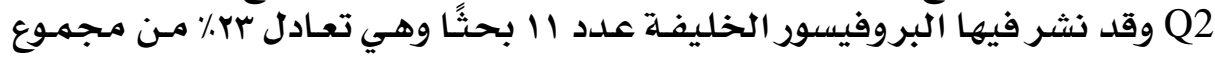

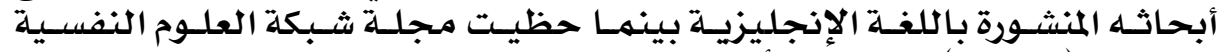

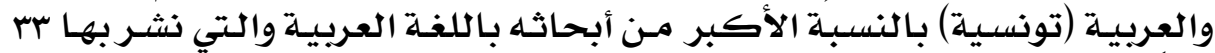

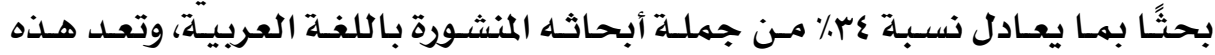

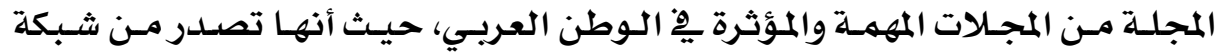

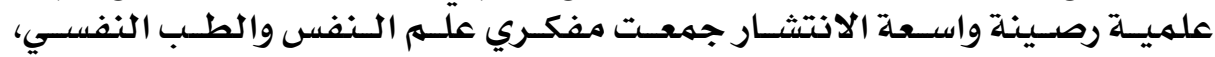

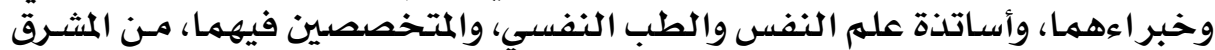

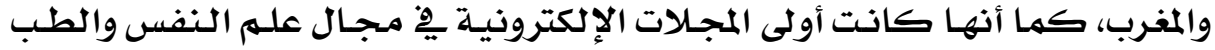

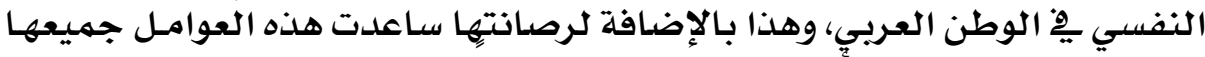

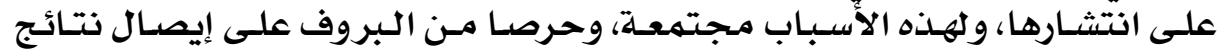

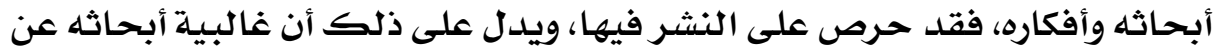

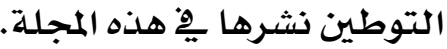

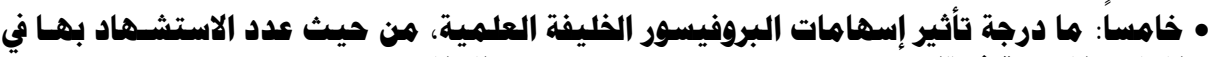

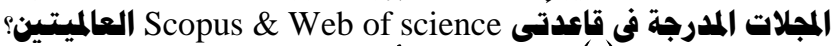
جذول (v) يعكس معامل تأثير ومستوى المجلات التي ثشر بها بروفسور الخليفت

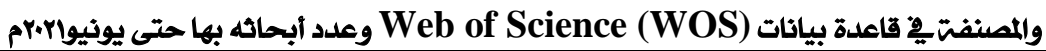

\begin{tabular}{|c|c|c|c|c|}
\hline المستوى & معامل تأثيّير & عدد الأبحاث & المجلة & 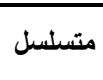 \\
\hline Q1 & 2.661 & 3 & JOURNAL OF CREATIVE BEHAVIOR & 1 \\
\hline Q2 & 2.471 & 1 & INTELLIGENCE & 2 \\
\hline Q2 & 2.311 & 2 & $\begin{array}{l}\text { PERSONALITY AND INDIVIDUAL } \\
\text { DIFFERENCES }\end{array}$ & 3 \\
\hline Q3 & 1.535 & 1 & PSYCHOLOGICAL REPORTS & 4 \\
\hline Q2 & 1.15 & 7 & MANKIND QUARTERLY & 5 \\
\hline Q3 & 2.201 & 1 & $\begin{array}{l}\text { *SCANDINAVIAN JOURNAL OF } \\
\text { INFECTIOUS DISEASES }\end{array}$ & 6 \\
\hline Q3 & 1.255 & 8 & $\begin{array}{l}\text { INTERNATIONAL JOURNAL OF } \\
\text { PSYCHOLOGY }\end{array}$ & 7 \\
\hline Q3 & 1.207 & 3 & JOURNAL OF BIOSOCIAL SCIENCE & 8 \\
\hline Q4 & 1.063 & 1 & $\begin{array}{l}\text { ASIAN JOURNAL OF SOCIAL } \\
\text { PSYCHOLOGY }\end{array}$ & 9 \\
\hline & & 27 & \multicolumn{2}{|l|}{ المجموع } \\
\hline
\end{tabular}

Source: Journal Citation Reports ${ }^{\mathrm{TM}} 2016^{*}$ 


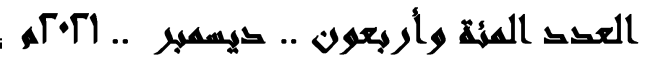

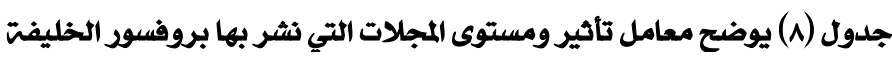

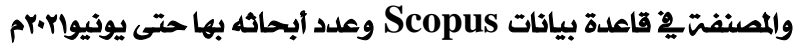

\begin{tabular}{|c|c|c|c|c|}
\hline المستوى & SJR & عدد & المجلة & متسلسل \\
\hline$\overline{\mathbf{Q 3}}$ & 0.246 & 4 & $\begin{array}{l}\text { Gifted and Talented } \\
\text { International }\end{array}$ & 1 \\
\hline - & - & 1 & $\frac{* * \text { Scandinavian Journal of }}{\text { Infectious Diseases }}$ & 2 \\
\hline$\overline{\mathbf{Q 1}}$ & 1.63 & 1 & Intelligence & $\overline{3}$ \\
\hline Q1 & $\mathbf{0 . 6 3}$ & 3 & $\begin{array}{c}\text { Journal of Creative } \\
\text { Behavior }\end{array}$ & 4 \\
\hline $\mathbf{Q 1}$ & 1.29 & 2 & $\begin{array}{l}\text { Personalitv and Individual } \\
\text { Differences }\end{array}$ & 5 \\
\hline$\overline{\mathbf{Q 2}}$ & 0.45 & 1 & $\begin{array}{c}\text { Asian Journal of Social } \\
\text { Psychology }\end{array}$ & 6 \\
\hline$\overline{\mathbf{Q 2}}$ & 0.44 & $\mathbf{1}$ & High Ability Studies & 7 \\
\hline$\overline{\mathbf{Q 2}}$ & 0.57 & $\bar{r}$ & $\begin{array}{c}\text { Journal of Biosocial } \\
\text { Science }\end{array}$ & 8 \\
\hline$\overline{\mathbf{Q 2}}$ & $\mathbf{0 . 1 2}$ & 1 & Journal of Islamic Studies & 9 \\
\hline $\mathbf{Q 2}$ & 0.26 & 9 & Mankind Quarterly & 10 \\
\hline $\mathbf{Q 2}$ & 0.47 & 1 & Psychological Reports & 11 \\
\hline & & 27 & \multicolumn{2}{|l|}{ 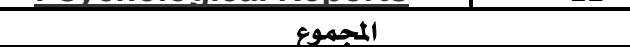 } \\
\hline
\end{tabular}

${ }^{* *}$ Scandinavian Journal of Infectious Diseases: Scopus coverage years: from

1969 to 2014 (coverage discontinued in Scopus)

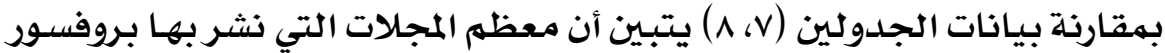

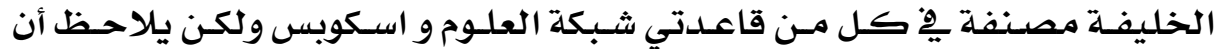

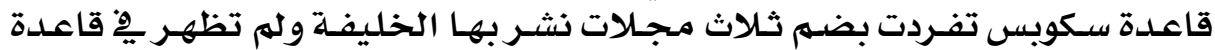

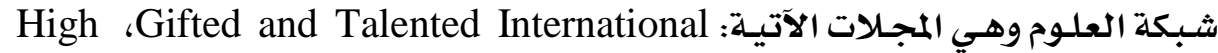

بوان Journal of Islamic Studies ،Ability Studies

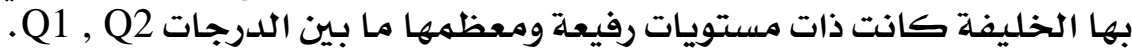

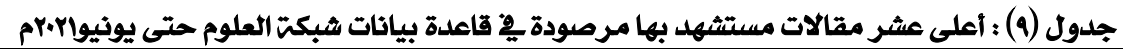

\begin{tabular}{|c|c|c|c|c|c|}
\hline عدد اللاستشعهادات & المشاركين يـ البحث & السنتة & 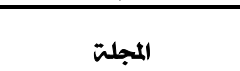 & عنوان البحث & الرقم \\
\hline 39 & $\begin{array}{l}\text { SALIH, } \\
\text {; KHALEEF, MAM } \\
\text { OH;BUSHARA, } \\
\text { M; TAHA, } \\
\text { ZB; MUSA, } \\
\text { ZA; KAMIL, } \\
\text { I; HOFVANDER, } \\
\text { Y' OLCEN, P }\end{array}$ & 1991 & $\begin{array}{l}\text { *SCANDINAVIAN } \\
\text { JOURNAL OF } \\
\text { INFECTIOUS } \\
\text { DISEASES }\end{array}$ & $\begin{array}{c}\text { LONG-TERM } \\
\text { SEQUELAE OF } \\
\text { CHILDHOOD } \\
\text { ACUTE } \\
\text { BACTERIAL- } \\
\text { MENINGITIS } \\
\text { IN A } \\
\text { DEVELOPING } \\
\text {-COUNTRY - } \\
\text { A STUDY } \\
\text { FROM THE } \\
\text { SUDAN }\end{array}$ & 1 \\
\hline 23 & $\begin{array}{c}\text { Khaleefa, } \\
\text { Omar; Sulman, } \\
\text { Afra; Lynn, Richard }\end{array}$ & 2009 & $\begin{array}{l}\text { JOURNAL OF } \\
\text { BIOSOCIAL } \\
\text { SCIENCE } \\
\end{array}$ & $\begin{array}{l}\text { AN INCREASE } \\
\text { OF } \\
\text { INTELLIGENC }\end{array}$ & 2 \\
\hline
\end{tabular}




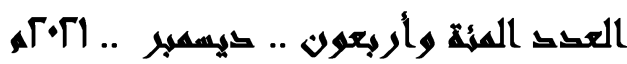

\begin{tabular}{|c|c|c|c|c|c|}
\hline & & & & $\begin{array}{c}\text { E IN SUDAN, } \\
1987-2007\end{array}$ & \\
\hline 23 & $\begin{array}{c}\text { Khaleefa, Omar; } \\
\text { Abdelwahid, S. B; } \\
\text { Abdulradi, F; } \\
\text { Lynn, Richard }\end{array}$ & 2008 & $\begin{array}{l}\text { PERSONALITY } \\
\text { AND } \\
\text { INDIVIDUAL } \\
\text { DIFFERENCES }\end{array}$ & $\begin{array}{l}\text { The increase of } \\
\text { intelligence } \\
\text { in Sudan } \\
1964-2006\end{array}$ & 3 \\
\hline 21 & $\begin{array}{c}\text {; Lynn, Khaleefa, Omar } \\
\text { Richard }\end{array}$ & 2008 & $\begin{array}{l}\text { MANKIND } \\
\text { QUARTERLY }\end{array}$ & $\begin{array}{c}\text { A Study of } \\
\text { Intelligence } \\
\text { in the United } \\
\text { Arab } \\
\text { Emirates } \\
\end{array}$ & 4 \\
\hline 19 & $\begin{array}{c}\text {; Lynn, Khaleefa, Omar } \\
\text { Richard }\end{array}$ & 2008 & $\begin{array}{l}\text { MANKIND } \\
\text { QUARTERLY }\end{array}$ & $\begin{array}{l}\text { Sex differences } \\
\text { on the } \\
\text { progressive } \\
\text { matrices: } \\
\text { Some data } \\
\text { from Syria }\end{array}$ & 5 \\
\hline 19 & $\begin{array}{l}\text { Irwing, Paul; Hamza, } \\
\text { Alya; Khaleefa, } \\
\text { Omar; Lynn, Richard }\end{array}$ & 2008 & $\begin{array}{l}\text { PERSONALITY } \\
\text { AND } \\
\text { INDIVIDUAL } \\
\text { DIFFERENCES }\end{array}$ & $\begin{array}{c}\text { Effects of } \\
\text { Abacus } \\
\text { training on } \\
\text { the } \\
\text { intelligence } \\
\text { of Sudanese } \\
\text { children }\end{array}$ & 6 \\
\hline 15 & $\begin{array}{l}\text { Khaleefa, OH; Erdos, } \\
\text { G; Ashria, IH }\end{array}$ & 1996 & $\begin{array}{l}\text { JOURNAL OF } \\
\text { CREATIVE } \\
\text { BEHAVIOR }\end{array}$ & $\begin{array}{l}\text { Creativity in an } \\
\text { indigenous } \\
\text { Afro-Arab } \\
\text { Islamic } \\
\text { culture: The } \\
\text { case of } \\
\text { Sudan }\end{array}$ & 7 \\
\hline 13 & $\begin{array}{l}\text { Khaleefa, OH; Erdos, } \\
\text { G; Ashria, IH }\end{array}$ & 1997 & $\begin{array}{l}\text { JOURNAL OF } \\
\text { CREATIVE } \\
\text { BEHAVIOR }\end{array}$ & $\begin{array}{c}\text { Traditional } \\
\text { education } \\
\text { and } \\
\text { creativity in } \\
\text { an Afro-Arab } \\
\text { Islamic } \\
\text { culture: The } \\
\text { case of } \\
\text { Sudan }\end{array}$ & 8 \\
\hline 11 & $\begin{array}{c}\text { Khaleefa, } \\
\text { Omar; Khatib, } \\
\text { Mohamed; Mutwakk } \\
\text { il, Mohied ; Lynn, } \\
\text { Richard }\end{array}$ & 2008 & $\begin{array}{l}\text { MANKIND } \\
\text { QUARTERLY }\end{array}$ & $\begin{array}{l}\text { Norms and } \\
\text { Gender } \\
\text { Differences } \\
\text { on the } \\
\text { Progressive } \\
\text { Matrices in } \\
\text { Sudan }\end{array}$ & 9 \\
\hline 8 & $\begin{array}{c}\text {; Lynn, Khaleefa, Omar } \\
\text { Richard }\end{array}$ & 2008 & $\begin{array}{l}\text { PSYCHOLOGICAL } \\
\text { REPORTS }\end{array}$ & $\begin{array}{c}\text { NORMATIVE } \\
\text { DATA FOR } \\
\text { RAVEN'S } \\
\text { COLOURED } \\
\text { PROGRESSIV } \\
\text { E MATRICES } \\
\text { SCALE IN } \\
\text { YEMEN }\end{array}$ & 10 \\
\hline
\end{tabular}

*Source: Journal Citation Reports ${ }^{\text {TM }} 2016$ 


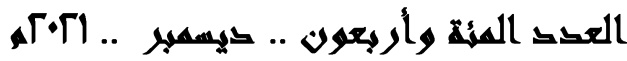

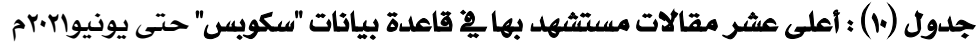

\begin{tabular}{|c|c|c|c|c|c|}
\hline الاستشثهادات & المشاركين يُ البحث & السنتة & المجلت & عنوان البحث & الرقم \\
\hline 67 & $\begin{array}{l}\text { Salih. } \\
\text { M.M.A. } \\
\text { Khaleefa. } \\
\text { O.H.,Bushara } \\
\text { M., B. Hofvande } \\
\text { r...Y., Olcén, P. }\end{array}$ & 1991 & $\begin{array}{l}\text { "*acandinav } \\
\text { ian Journal } \\
\text { of } \\
\text { Infectious } \\
\text { Diseases }\end{array}$ & $\begin{array}{l}\text { Lona term seauelae } \\
\text { of childhood acute } \\
\text { bacterial meninaitis } \\
\text { in a develoning } \\
\text { countrv: A study } \\
\text { from the Sudan } \\
\text { fom }\end{array}$ & - \\
\hline 34 & $\begin{array}{l}\text { Khaleefa. } \\
\text { Sulman. O. } \\
\text { A., Lynn, R. }\end{array}$ & 2009 & $\begin{array}{l}\text { Journal of } \\
\text { "Biosocial" } \\
\text { "Science" } \\
\text { Science }\end{array}$ & $\begin{array}{c}\text { An increase of } \\
\text { intelliaence in } \\
\text { Sudan, 1987-2007 } \\
\end{array}$ & 1 \\
\hline 31 & $\begin{array}{l}\text { Khaleefa. } \\
\text { Lynn, R.O. }\end{array}$ & 2008 & $\begin{array}{l}\text { Mankind } \\
\text { Quarterly }\end{array}$ & $\begin{array}{l}\text { A studv of } \\
\text { intelliaence in the } \\
\text { United Arab } \\
\text { Emirates }\end{array}$ & 2 \\
\hline 27 & $\begin{array}{l}\text { Khaleefa, } \\
\text { O. } \\
\text { Abdelwahid. } \\
\text { S.B.Abdulra } \\
\text { di, F. Lynn, } \\
\text { R. }\end{array}$ & 2008 & $\begin{array}{l}\text { Personality } \\
\text { and } \\
\text { Individual } \\
\text { Differences }\end{array}$ & $\begin{array}{l}\text { The increase of } \\
\text { intelliaence in } \\
\text { Sudan 1964-2006 } \\
\end{array}$ & 3 \\
\hline 27 & $\begin{array}{l}\text { Khaleefa. } \\
\text { Lynn, R.O. }\end{array}$ & 2008 & $\begin{array}{l}\text { Mankind } \\
\text { Quarterly' }\end{array}$ & $\begin{array}{c}\text { Sex differences on } \\
\text { the Proaressive } \\
\text { Matrices: Some data } \\
\text { from Syria }\end{array}$ & 4 \\
\hline 20 & $\begin{array}{l}\text { Trwind. } \\
\text { Hamza. P. } \\
\text { A-Khaleefa, } \\
\text { O.- Lynn, R. }\end{array}$ & 2008 & $\begin{array}{l}\text { Personality } \\
\text { and } \\
\text { Individual } \\
\text { Differences }\end{array}$ & $\begin{array}{l}\text { Effrects of Abacus } \\
\text { trainind on the } \\
\text { intellidence of } \\
\text { Sudanese children }\end{array}$ & 5 \\
\hline 19 & $\begin{array}{l}\text { Khaleefa. } \\
\text { Erdos. O.H. } \\
\text { G.. Ashria, } \\
\text { I.H. }\end{array}$ & 1997 & $\begin{array}{l}\text { Journal of } \\
\text { Creative } \\
\text { Behavior }\end{array}$ & $\begin{array}{l}\text { Traditional } \\
\text { education and } \\
\text { creativitv in an Afro- } \\
\text { Arab Islamic culture: } \\
\text { The case of Sudan }\end{array}$ & 6 \\
\hline 17 & $\begin{array}{l}\text { Khaleefa. } \\
\text { Khatib. O. } \\
\text { M.A., Mutwak } \\
\text { kil. } \\
\text { M.M., Lynn, } \\
\text { R. }\end{array}$ & 2008 & $\begin{array}{l}\text { Mankind } \\
\text { Quarterly }\end{array}$ & $\begin{array}{l}\text { Norms and oender } \\
\text { differences on the } \\
\text { nroaressive } \\
\text { matrices in Sudan }\end{array}$ & 7 \\
\hline 17 & $\begin{array}{l}\text { Khaleefa. } \\
\text { Erdos. O.H, } \\
\text { E., Ashria, } \\
\text { I.H. }\end{array}$ & 7996 & $\begin{array}{l}\text { Journal of } \\
\text { Creative } \\
\text { Behavior }\end{array}$ & $\begin{array}{c}\text { Creativitv in an } \\
\text { indiaenous Afro- } \\
\text { Arab Islamic culture: } \\
\text { The case of Sudan }\end{array}$ & 8 \\
\hline 11 & $\begin{array}{l}\text { Khaleefa. } \\
\text { Lynn, R.O. }\end{array}$ & 2008 & $\begin{array}{l}\text { Psvcholoai } \\
\text { cal Reports }\end{array}$ & $\begin{array}{l}\text { Normative data for } \\
\text { raven's-coloured } \\
\text { vroaressive } \\
\text { matrices scale in } \\
\text { Yemen }\end{array}$ & 9 \\
\hline 11 & $\begin{array}{l}\text { Khaleefa } \\
\text { Erdos. O.H. } \\
\text { E. G., Ashria, } \\
\text { I.H. }\end{array}$ & 1996 & $\begin{array}{c}\text { Journal of } \\
\text { Creative } \\
\text { Behavior }\end{array}$ & $\begin{array}{l}\text { Gender and } \\
\text { creativitv in an Afro- } \\
\text { Arab Islamic culture: } \\
\text { The case of Sudan } \\
\end{array}$ & $\overline{10}$ \\
\hline
\end{tabular}

${ }^{\star \star}$ Scandinavian Journal of Infectious Diseases: Scopus coverage years: from 1969 to 2014 (coverage discontinued in Scopus).

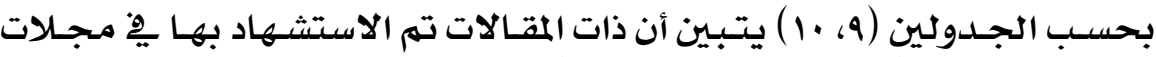

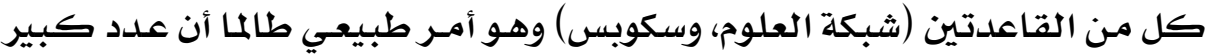




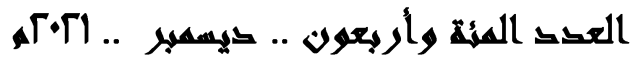

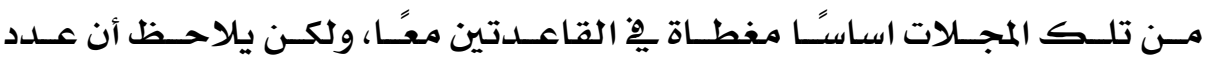

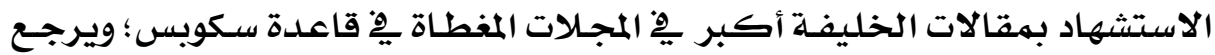

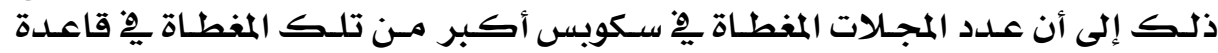
شبكة العلوم.

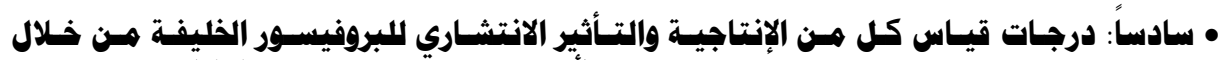

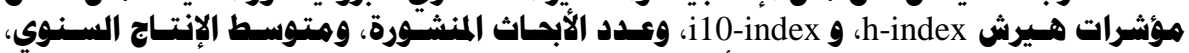

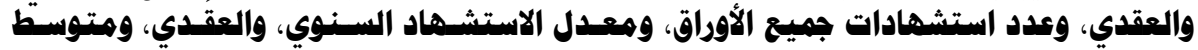

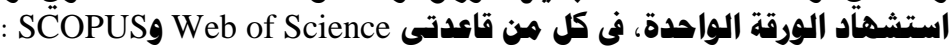

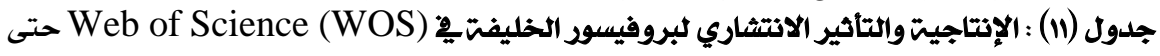
يونيوابونrم

\begin{tabular}{|c|c|c|}
\hline درجت المؤثر & اسم المؤشير & م \\
\hline 19 & عدد الأبحاث & 1 \\
\hline 7 & مؤثر هيرث h-index & $r$ \\
\hline$\overline{6}$ & i10-index & $r$ \\
\hline $\mathbf{0 . 7 3}$ & متوسط الإنتاج السنوي & $\varepsilon$ \\
\hline 7.3 & متوسط الإنتاج العقدي & 0 \\
\hline 87 & الأبحاث التى استشهلت بإبحاثه & 7 \\
\hline 79 & الأبحاث التى استشهلت بابحاثه، فير محسوب من ضمنها أبحاثه & $v$ \\
\hline 149 & عدد جميع الاستشهادات & $\Lambda$ \\
\hline 131 & عدد الاستشهادات بلدون الاستشهاد الذاتى & 9 \\
\hline 7.84 & متوسط استشهاد الورقت الواحلدة & 1. \\
\hline $\mathbf{5 . 7 3}$ & معدل الاستشهاد السنوي & 11 \\
\hline $\mathbf{5 7 . 3 1}$ & معدل الاستشهاد العقدي & ir \\
\hline
\end{tabular}

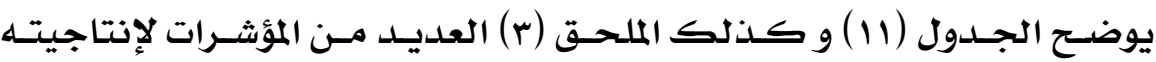

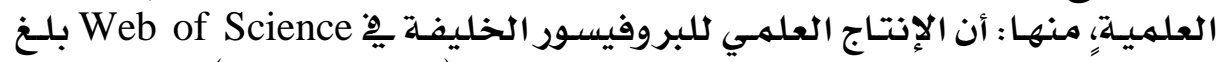

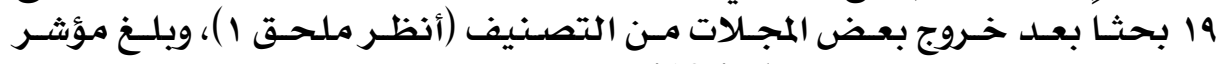

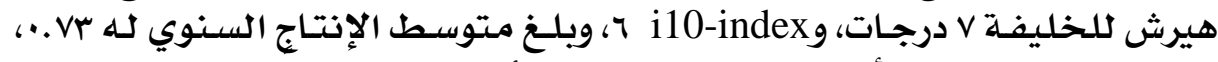

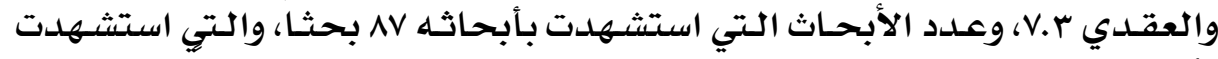

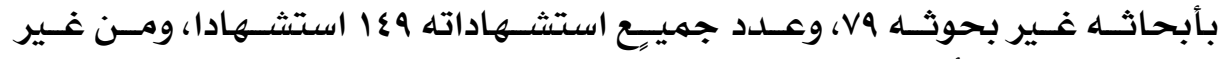

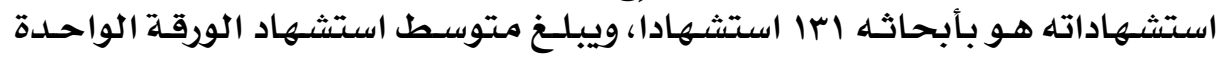

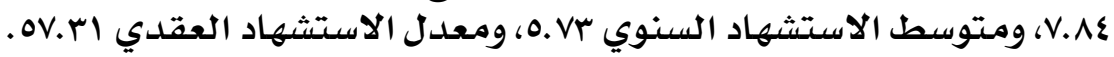

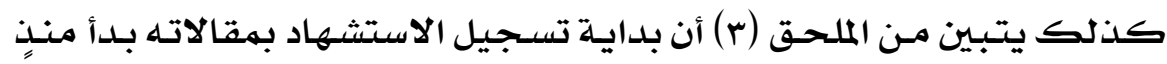

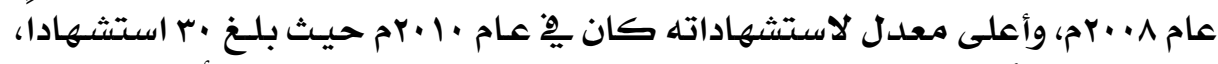

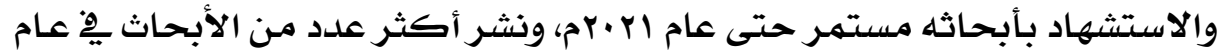

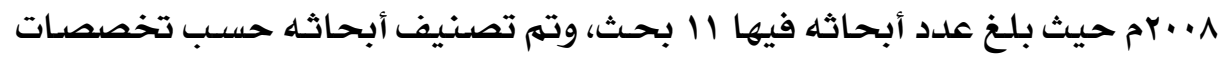

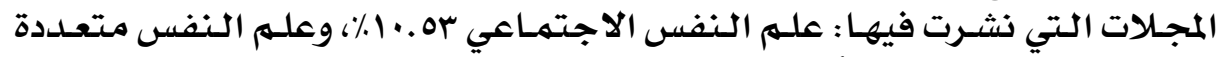

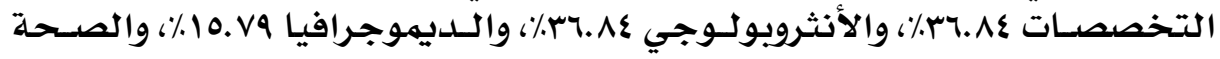

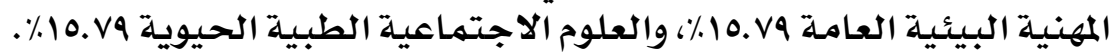




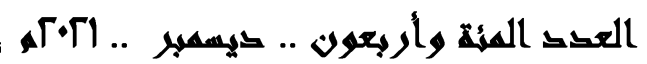

جلدول (rا) : الإنتاجيت والتأثير الانتشاري لبروفيسور الخليفتي 2 SCOPUS حتى يونيواب.rم

\begin{tabular}{|c|c|c|}
\hline درجت المؤثر & المؤثر & م \\
\hline 26 & مدد الأبحاث التى مازالت \& SCOPUS & 1 \\
\hline 10 & مؤثر هيرثي h-index & $r$ \\
\hline 12 & i10-index & $r$ \\
\hline 1 & متوسط الإنتاج السنوي & $\varepsilon$ \\
\hline 10 & متوسط الإنتاج العقدى & 0 \\
\hline $\mathbf{1 7 5}$ & عدد الأبحاث التي استشهلت بابحاث الخليفت & 7 \\
\hline 288 & عدد جميع الاستشهادات & $v$ \\
\hline $\mathbf{1 1 . 0 8}$ & متوسط استثهاد الورقت الواحلة & $\Lambda$ \\
\hline 11.08 & معدل الاستشهاد السنوي & 9 \\
\hline 110.8 & معدل الاستشهاد العقدي & 1. \\
\hline
\end{tabular}

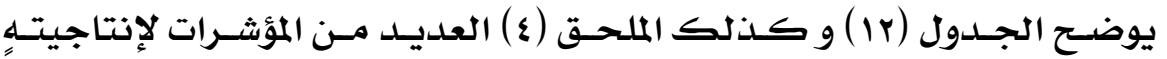

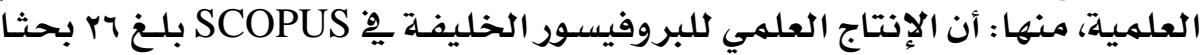

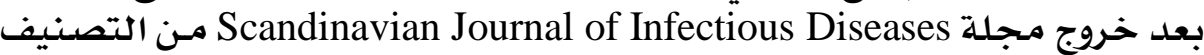

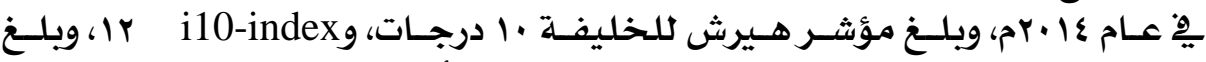

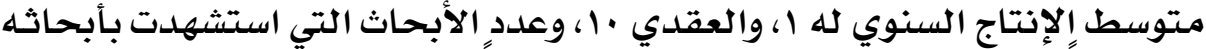

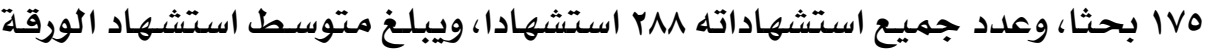

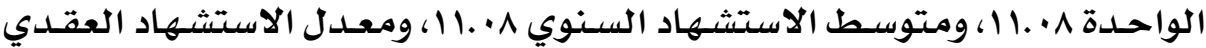

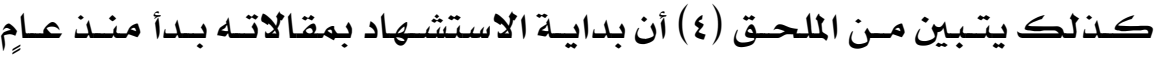

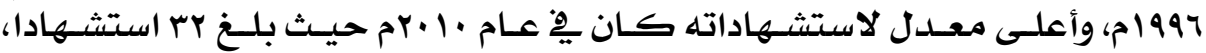

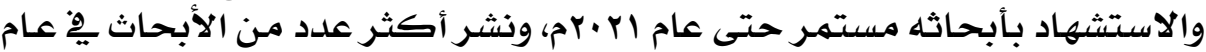

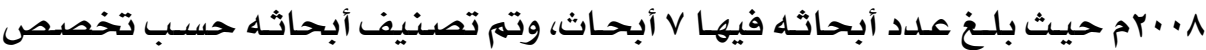

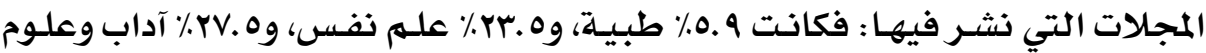

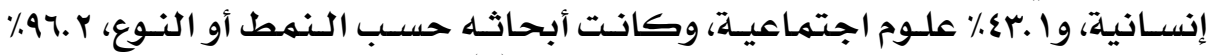

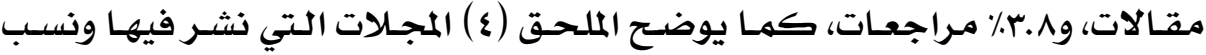
النشـر مانش

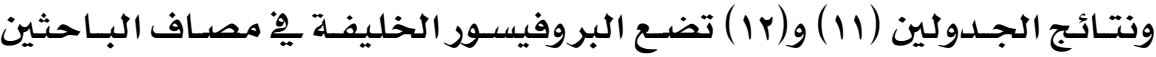

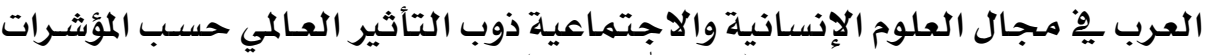

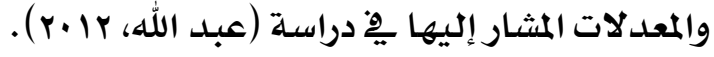

• الخفاتمة:

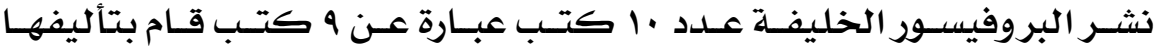

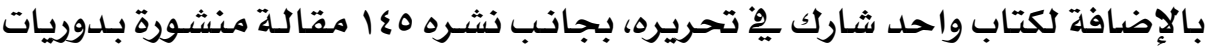

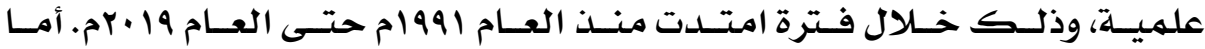

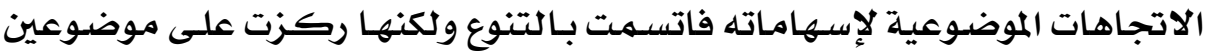

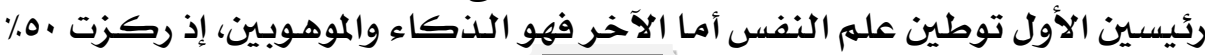




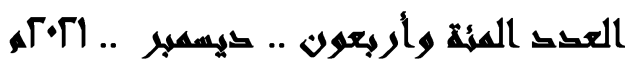

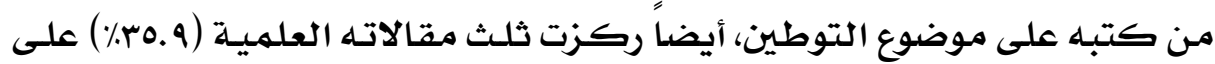

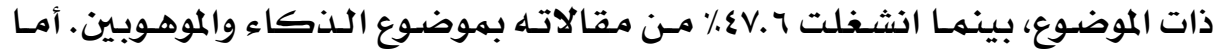

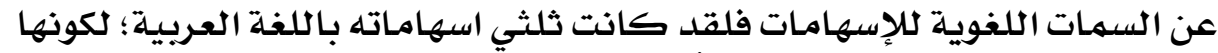

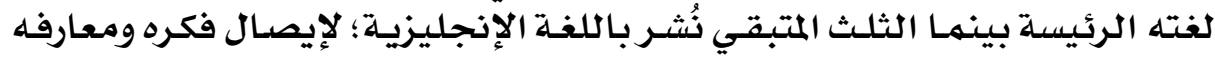

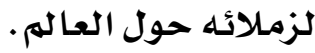

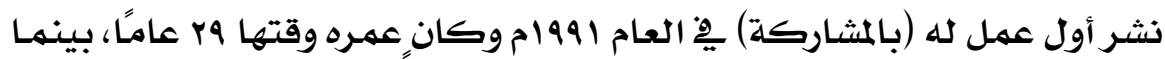

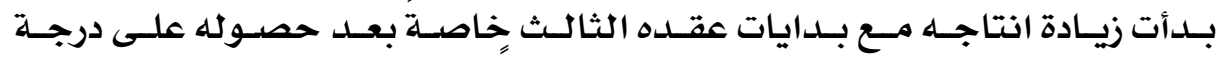

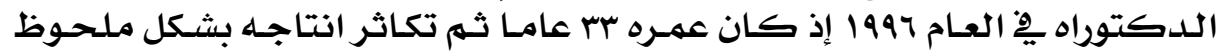

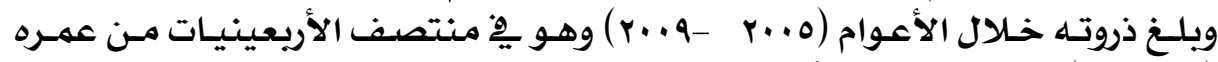

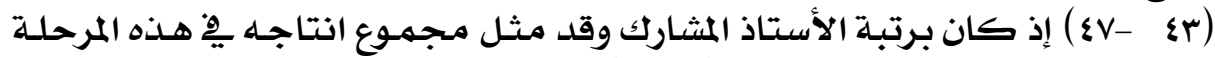

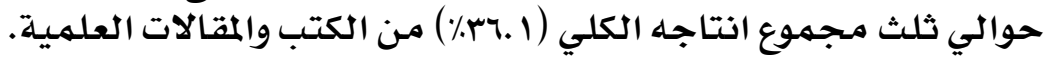

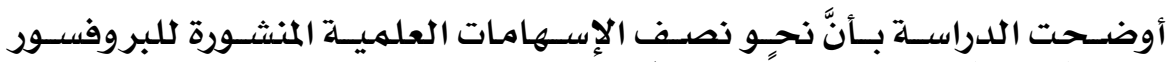

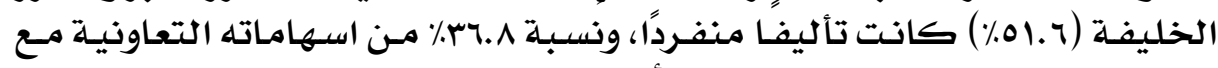

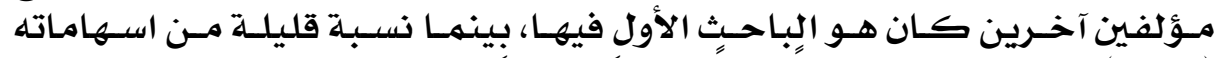

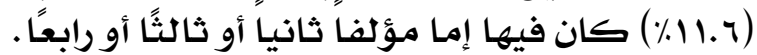

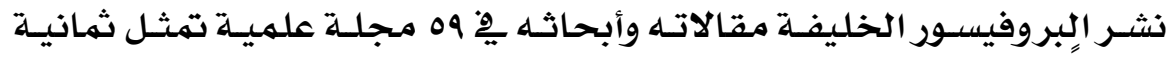

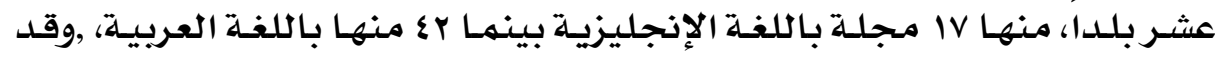

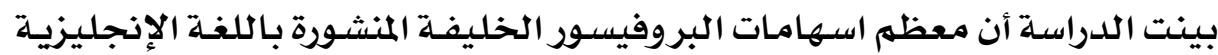

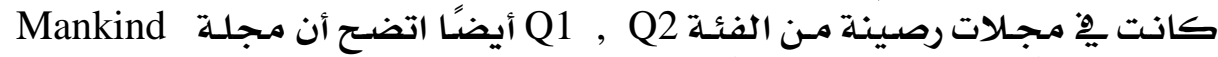

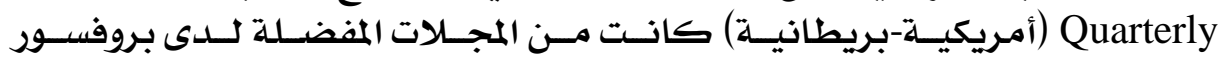

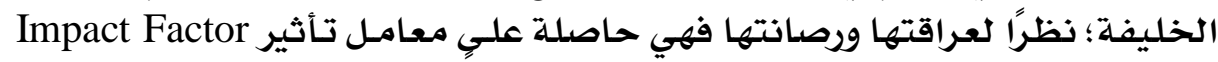

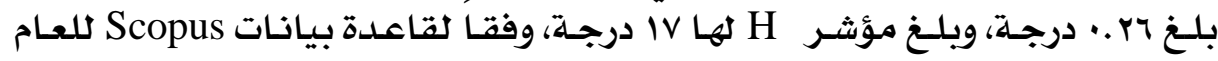

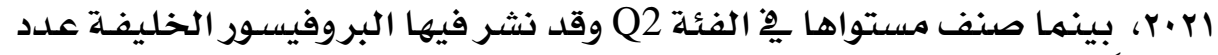

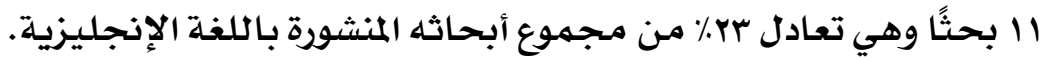

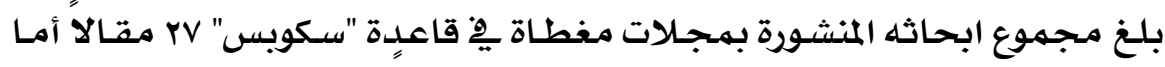

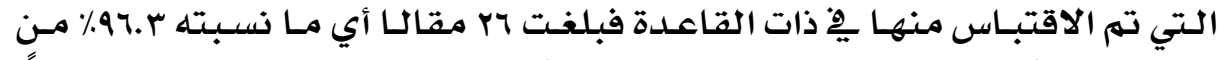

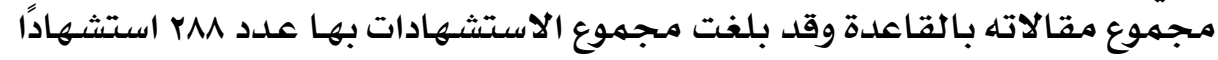

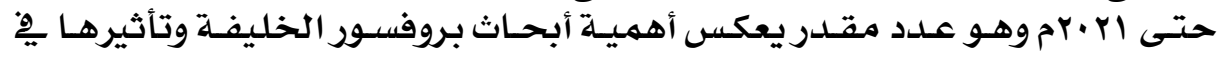

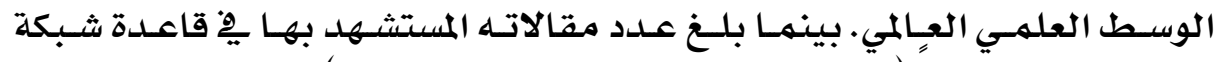

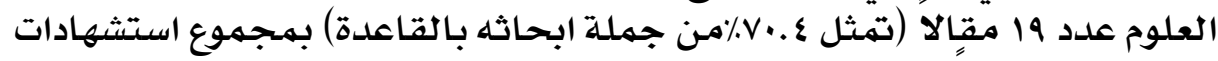

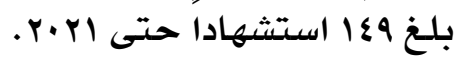

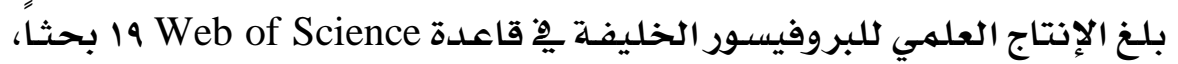

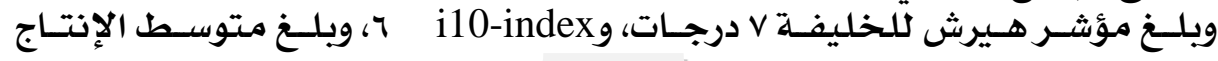




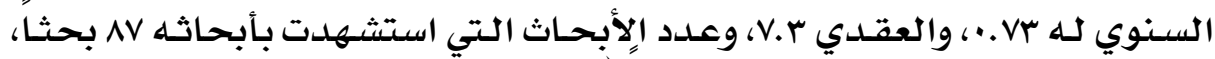

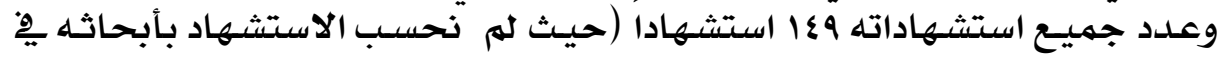

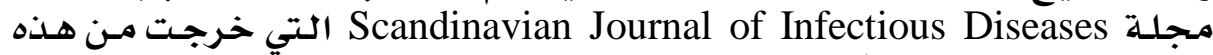

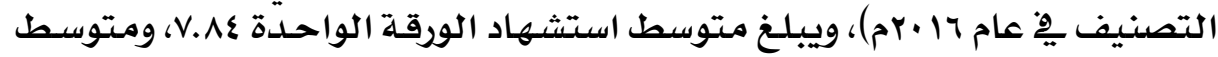

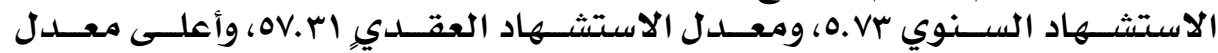

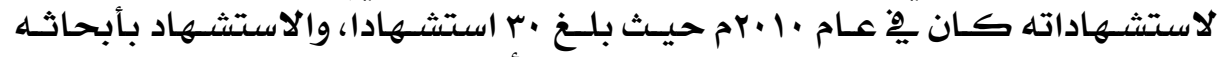

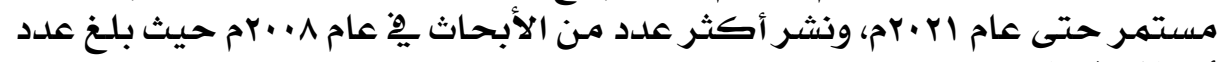

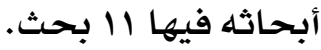

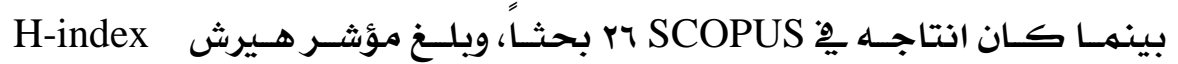

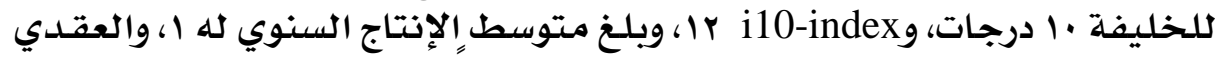

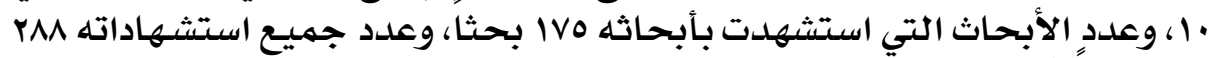

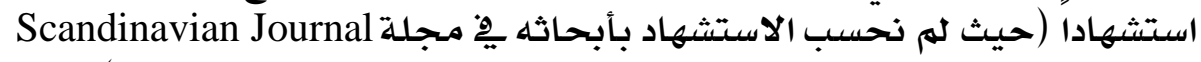
متؤ Infectious Diseases

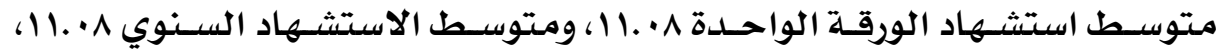
ومعدل الاستشهاد العقدي 1. •.11.

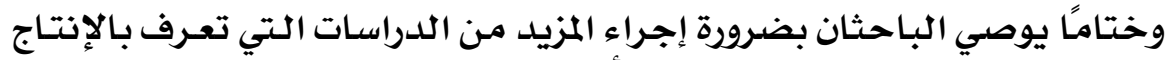

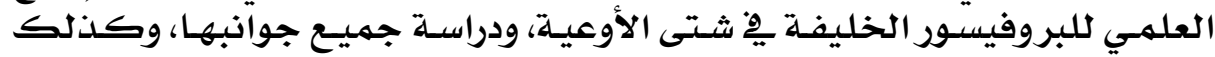

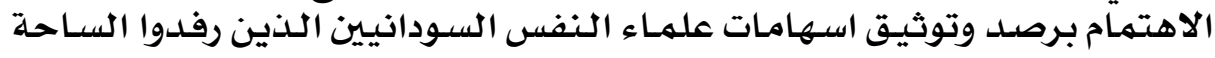

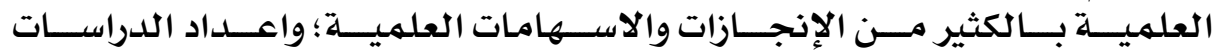

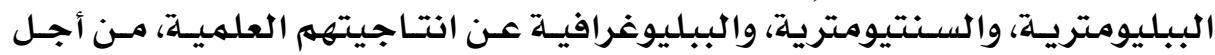

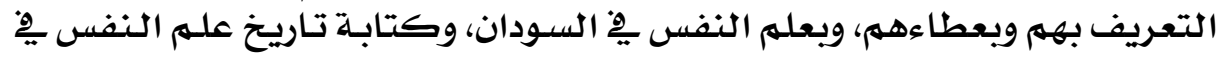

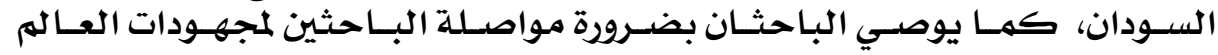

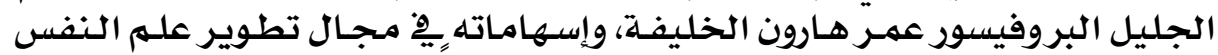

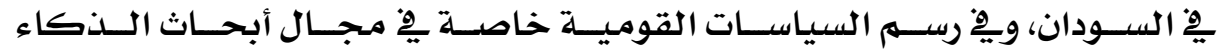

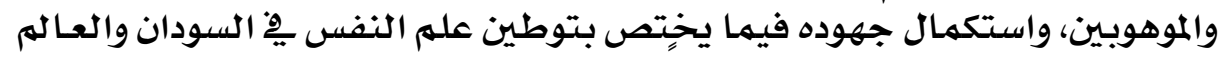

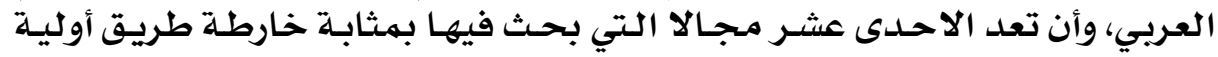

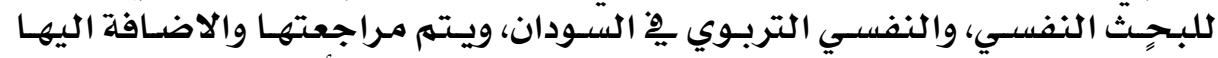

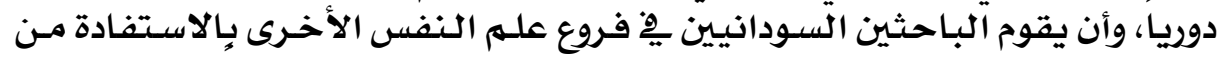

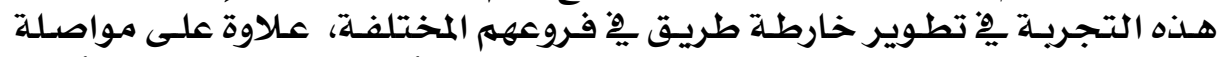

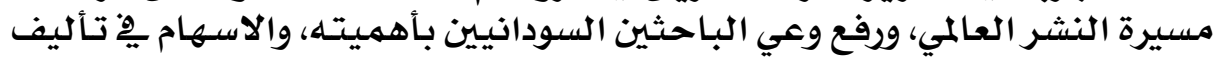
الكتب العلمية.

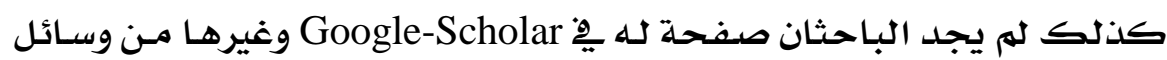

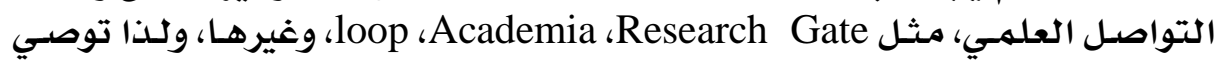

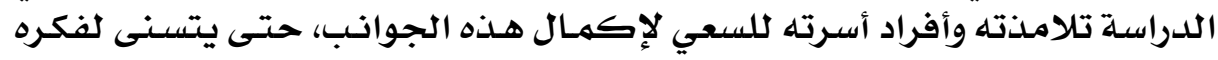

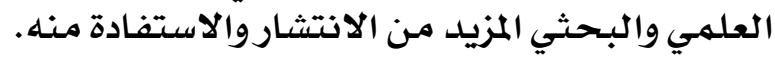




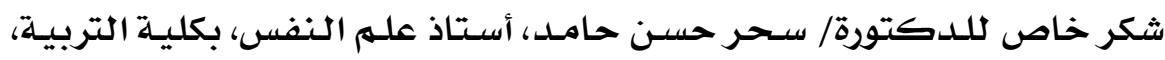

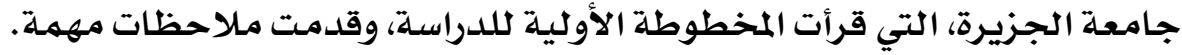

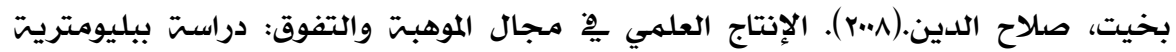

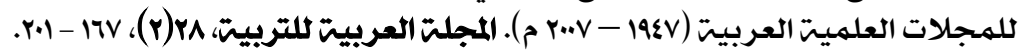

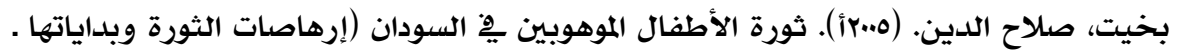

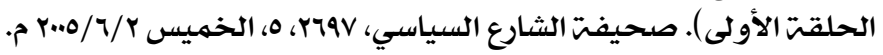

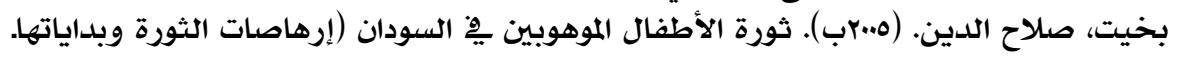

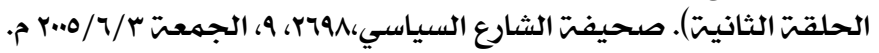

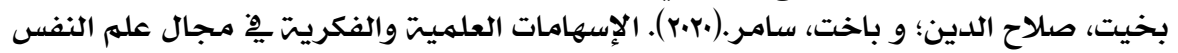

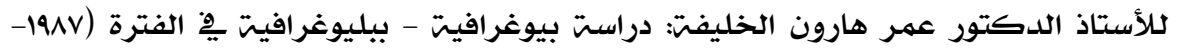

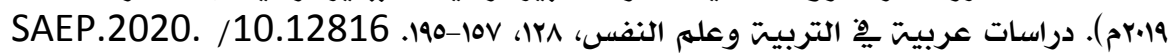
127127

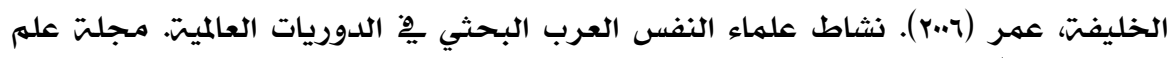

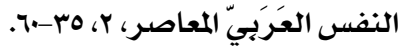

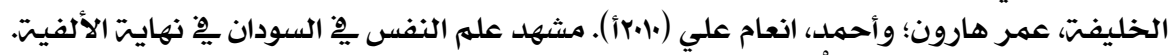

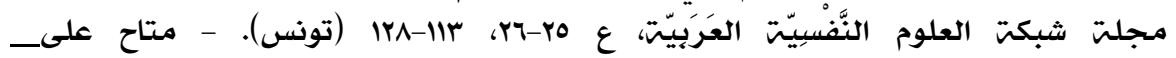
http://arabpsynet.com/Archives/OP/eJ2526OmarHarounKaleefa\&Ina amAhmed.pdf

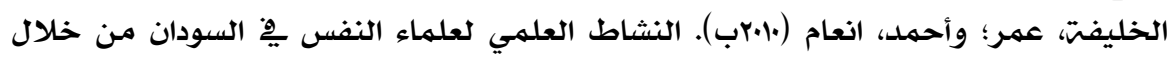

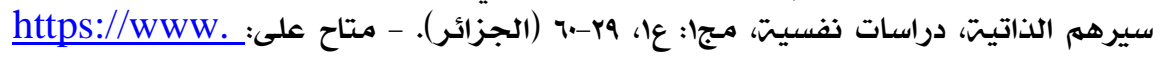
Asjp.cerist.dz/en/downArticle/288/1/1/9128

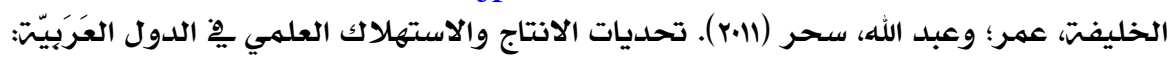

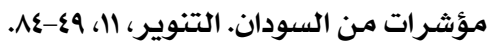

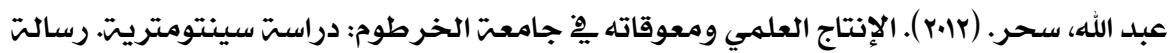

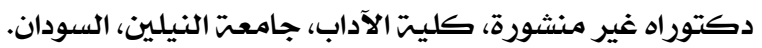

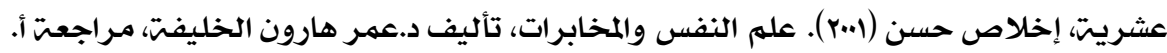

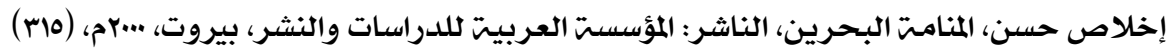

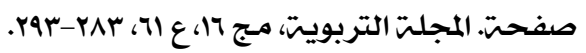

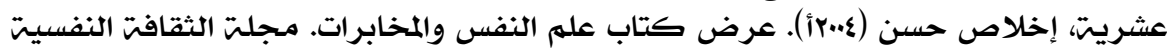

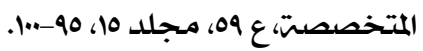

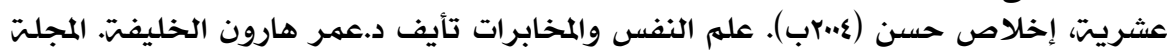

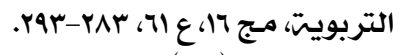

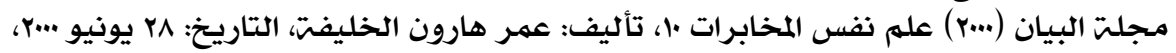
https://www.albayan.ae/one-world/2000-06-28-1.1085100 


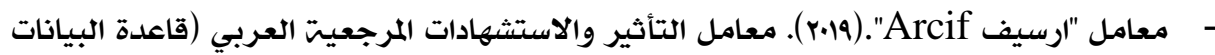

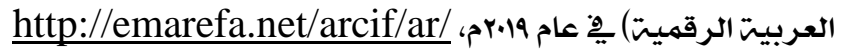

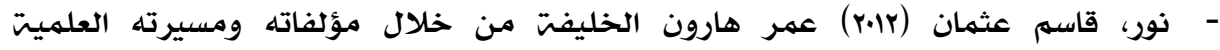

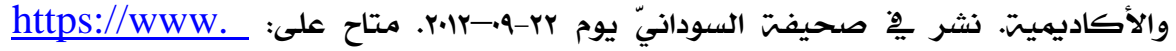
sudaress.com/alsudani/10180

- Hartshorne, J.; \& Germine, L.(2015). When does cognitive functioning peak? The asynchronous rise and fall of different cognitive abilities across the lifespan.Psychological Science, 26,4, 433-443. https://doi.org/10.1177/0956797614567339

- Polanin, J. R., Tanner-Smith, E. E., \& Hennessy, E. A. (2016). Estimating the difference between published and unpublished effect sizes a metareview. Review of Educational Research, 86, 207-236. doi:10.3102/0034654315582067

\section{潾潾潘潾潾}

